Const ruct i on of novel nanosecond temper at ure j ump appar at uses appl i cabl e to Raman measur ement $s$ and di rect observati on of transi ent t emper at ure

\begin{tabular}{|l|l|}
\hline 著者 & $\begin{array}{l}\text { YAMAMOTO Kohj i , M ZUTAN Yasuhi sa, W TAGAWA } \\
\text { Tei zo }\end{array}$ \\
\hline $\begin{array}{l}\text { j our nal or } \\
\text { publ i cat } \mathrm{i} \text { on } \mathrm{t} \text { i t l e }\end{array}$ & Appl i ed spect r oscopy \\
\hline vol une & 54 \\
\hline nunber & 11 \\
\hline page $\mathrm{r}$ ange & $1591-1604$ \\
\hline year & $2000-11$ \\
\hline URL & ht t p: //hdl . handl e. net $/ 10098 / 3030$ \\
\hline
\end{tabular}




\title{
Construction of Novel Nanosecond Temperature Jump Apparatuses Applicable to Raman Measurements and Direct Observation of Transient Temperature
}

\author{
KOHJI YAMAMOTO, YASUHISA MIZUTANI, and TEIZO KITAGAWA* \\ Department for Functional Molecular Science, School of Mathematical and Physical Science, The Graduate University for \\ Advanced Studies, Myodaiji, Okazaki 444-8585, Japan (K.Y., Y.M., T.K.); and Institute for Molecular Science, Okazaki National \\ Research Institutes, Myodaiji, Okazaki 444-8585, Japan (Y.M., T.K.)
}

\begin{abstract}
Two types of nanosecond temperature jump ( $T$-jump) apparatuses applicable to time-resolved Raman measurem ents were constructed. T-jump was achieved by direct heating of water using near-infrared (NIR) pulses at $1.89 \mu \mathrm{m}$ in one type and at $1.56 \mu \mathrm{m}$ in the other. The two NIR pulses were generated through stimulated Raman scattering (SRS) of $\mathrm{H}_{2}$ or $\mathrm{D}_{2}$ excited by the fundamental line of a Q-switched Nd:YAG laser, in which a single-pass configuration with $\mathrm{H}_{2}$ was sufficient for $1.89 \mu \mathrm{m}$ pulses but a seeding-amplification configuration with $D_{2}$ was necessary for $1.56 \mu \mathrm{m}$ pulses. The seeding-amplification configuration yielded significant improvements in conversion efficiency, pulse-to-pulse stability, and beam quality. These apparatuses were applied to transient Raman measurements of $\mathrm{MoO}_{4}{ }^{2-}$ solution, and transient temperatures of the heated volume were determined from ratios of anti-Stokes to Stokes Raman intensities. Temporal behaviors of the temperature of the heated volume upon illumination of nanosecond heat pulses at 1.89 or 1.56 $\mu \mathrm{m}$ were explored, and its applicability to studies on the primary process of thermal reactions was examined. It became clear that the continuation time of raised temperature is determined only by the replacement of the sample in the case of a thick cell and by both thermal transfer and sample replacement in the case of a thin cell, while thermal diffusion is not effective for either cell.
\end{abstract}

Index Headings: Temperature jump; Near-infrared generation; Stimulated Raman scattering; Time-resolved Raman spectroscopy; Spectroscopic techniques; Transient temperature; Thermal diffusion; Thermal transfer.

\section{INTRODUCTION}

Chemical reactions can be categorized into photoreactions and thermal reactions according to inducing origins. In investigations of the primary process of these reactions, time-resolved spectroscopy combined with various kinds of relaxation methods have been used. ${ }^{1}$ Raman spectroscopy is so sensitive to molecular structures and the environments around molecules that it gives more detailed information about molecular states than absorption and fluorescence spectroscopy, and accordingly this technique has been increasingly used to monitor chemical reactions. As for the investigation of the initial process of photoreactions by Raman spectroscopy, time resolution has reached the level of Fourier transform limitation of the probe pulse. ${ }^{2,3}$ In contrast, fast processes of thermal reactions, which are more widely seen in nature, have been little investigated with Raman spectroscopy so far, because of the lack of a suitable rapid heating method at high repetition. However, Raman spectroscopy is a powerful tool for studies on structural changes in fast pro-

Received 5 May 2000; accepted 28 July 2000.

* Author to whom correspondence should be sent. cesses of thermal reactions if the rapid heating method applicable to time-resolved Raman measurements is available. Therefore, construction of such a rapid heating apparatus is very desirable for studies on thermal reactions.

Among various methods of temperature jump (T-jump) used to investigate thermal reactions, ${ }^{1,4}$ the laser-induced T-jump method can be applied to high-repetition measurements. ${ }^{5,6}$ Laser-induced T-jump is achieved (1) by direct heating of water ${ }^{4-14}$ or (2) by thermal energy transfer from photoexcited dyes. ${ }^{15}$ In case 1 , overtones or combinations of vibrations of water (solvent) are excited by a near-infrared (NIR) pulse; while in case 2, dissolved dyes are electronically excited by visible laser pulses, and subsequently surrounding solvent molecules are heated through nonradiative relaxation of dyes. Thus, in both cases, parts of the solvent molecules are directly or indirectly heated upon laser illumination. The laser-induced T-jump is completed when thermal equilibration is established between the heated solvent molecules and all the other solvent molecules. In the first T-jump case, NIR pulses are generated through Raman shifts of the fundamental $(1.064 \mu \mathrm{m})$ of a $\mathrm{Nd}$ :YAG laser with liquid $\mathrm{N}_{2}$ $(1.41 \mu \mathrm{m})^{7,8}$ or with molecular gases, ${ }^{3-6,9-13}$ while they can also be generated by the difference mixing of two dye laser outputs by $\mathrm{LiNbO}_{3}$ crystal $(\sim 2.0 \mu \mathrm{m}) .{ }^{14}$ Asher and co-workers succeeded in combining time-resolved Raman spectroscopy with laser T-jump techniques to unravel the initial process of unfolding of some small peptide. ${ }^{5,16}$

In this study T-jump was achieved through direct heating of water by NIR pulses, which were obtained with the stimulated Raman effect of $\mathrm{H}_{2}$ or $\mathrm{D}_{2}$ excited by the fundamental line of a Q-switched Nd:YAG laser. Here three types of NIR generation methods including the single-pass, half-resonator, and seeding-amplification systems will be explained first. The performances of two Tjump apparatuses constructed here will be described in detail, and the observed transient temperatures attained will be compared. The transient temperature was determined from the intensity ratios of anti-Stokes to Stokes bands of molybdate ions $\left(\mathrm{MoO}_{4}{ }^{2-}\right)$ in water. Finally, the characteristics of the NIR generation by $\mathrm{H}_{2}$ and $\mathrm{D}_{2}$, the temporal limitations on the laser-induced T-jump experiments with high-repetition measurements, and the applicability of two types of T-jump apparatuses to nonresonant Raman measurements of protein will be discussed. Hereafter an NIR pulse used for T-jump is called a heat pulse. 


\section{DESIGN OF T-JUMP APPARATUS}

Choice of Raman Shifting Media. NIR pulses can be generated as the first Stokes line in stimulated Raman scattering (SRS) of Raman media from the fundamental (1.064 $\mu \mathrm{m})$ of a Nd:YAG laser. Generally low thresholds for selffocusing and optical breakdown in solids and liquids and in addition the appearance of bubbles in liquids make it impossible to use these media as high-efficiency converters for SRS. Since these problems are less severe, gases are suitable to Raman media for this purpose. Hydrogen ${ }^{4,5}$ and methane $\mathrm{e}^{9-12}$ are most widely used on account of their relatively large Raman gain coefficients and large energy shifts, while deuterium is also usable: ${ }^{6,13} v\left[\mathrm{H}_{2}, \mathrm{Q}(1)\right]=$ $4155 \mathrm{~cm}^{-1} ; v\left[\mathrm{D}_{2}, \mathrm{Q}(2)\right]=2987 \mathrm{~cm}^{-1} ; v\left[\mathrm{CH}_{4}, \mathrm{Q}\right]=2917$ $\mathrm{cm}^{-1}$. The wavelengths of the first Stokes lines of $\mathrm{H}_{2}, \mathrm{D}_{2}$, and $\mathrm{CH}_{4}$ upon excitation with $1.064 \mu \mathrm{m}$ are $1.89,1.56$, and $1.54 \mu \mathrm{m}$, respectively. However, $\mathrm{CH}_{4}$ was partially photoreactive and caused more critical problems upon prolonged pumping; ${ }^{17}$ it underwent photodissociation upon excitation by strong $1.064 \mu \mathrm{m}$ pulses, and the dissociated carbons were deposited on the window, resulting in damage to the window in successive generation of NIR. $\dagger$ Therefore, in this laser-induced T-jump experiment, $\mathrm{H}_{2}$ and $\mathrm{D}_{2}$ gases were used as Raman media for generation of NIR.

Requisite Intensity of Heat Pulses and Sample Thickness for Uniform T-jump. It is quite important to heat a sample uniformly, but a temperature gradient is produced because the intensity of a heat pulse decreases as it proceeds from the surface to inside due to absorption. To overcome this problem, it is helpful to illuminate the sample from both sides with two heat pulses. Sample thickness is also important for uniform heating. Thin samples must be used for illumination of heat pulses at wavelengths where the absorption coefficient of water is large. The absorption coefficients of water at 1.89 and $1.56 \mu \mathrm{m}$ are 61 and $4 \mathrm{~cm}^{-1}, 7$ respectively (the former was determined in this study from the observed absorbances of water at $1.89 \mu \mathrm{m}$ for cell thicknesses of 25, 50,100, and $200 \mu \mathrm{m}$ ). Accordingly, an approximately $15 \times$ thicker cell can be used for $1.56 \mu \mathrm{m}$ heating than that for 1.89 $\mu \mathrm{m}$ heating under the same heating conditions.

Suppose that the intensity of a heat pulse is $100 \mathrm{~mJ}$ and the sample is illuminated by its equally divided two parts $(50 \mathrm{~mJ}$ each) from both sides in the counter-propagating geometry, as illustrated in the upper part of Fig. 1 . The temperature profiles of the illuminated volume calculated with the values of absorption coefficients of water mentioned above are delineated in the lower part of Fig. 1, where the conditions are as follows: (A) $140 \mu \mathrm{m}$ thick water is heated by $1.89 \mu \mathrm{m}$ pulses with $3 \mathrm{~mm}$ diameter, and (B) $2 \mathrm{~mm}$ thick water is heated by $1.56 \mu \mathrm{m}$ pulses with $1.5 \mathrm{~mm}$ diameter. The averaged temperature rises by 1.89 and $1.56 \mu \mathrm{m}$ pulses were estimated to be 20.8 and

\footnotetext{
$\dagger$ We tried successive generation of $1.54 \mu \mathrm{m}$ NIR with compressed methane, at $10 \mathrm{~Hz}$ repetition in configurations $\mathbf{A}$ and $\mathbf{B}$ (shown later). By prolonged pumping with $1.064 \mu \mathrm{m}$ light of $560 \mathrm{~mJ}$, an insidewindow surface of a Raman shifter was damaged in the two configurations. The reason for this damage is considered to be that photodissociated carbon atoms formed particles, which stuck to the inside surface of windows, and that the carbon particles were burned by intense pump light.
}
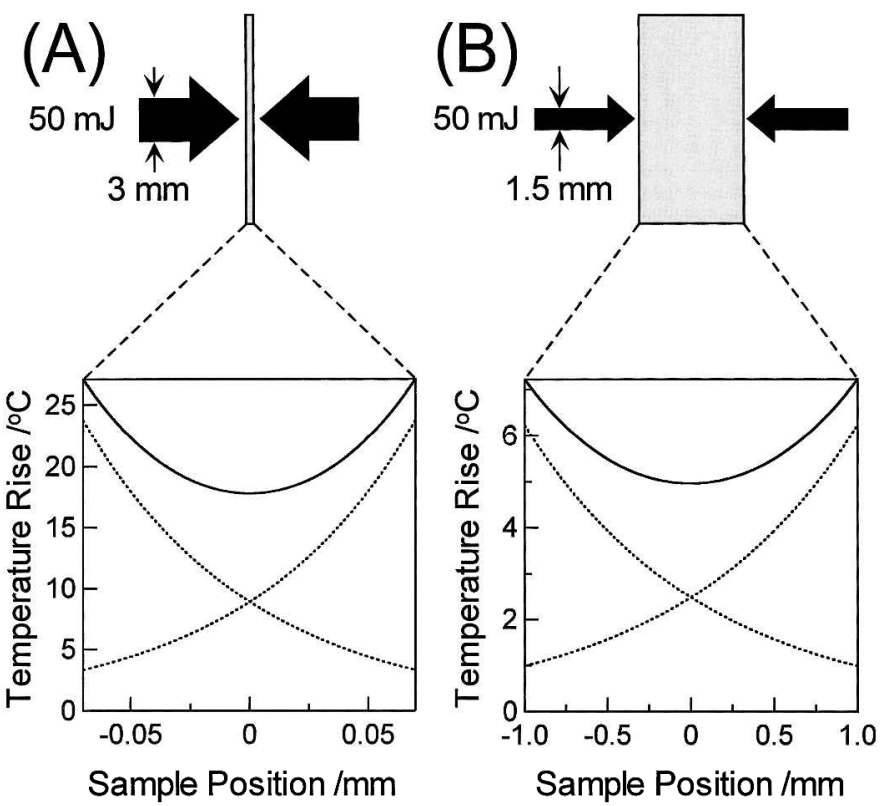

FIG. 1. Estimated temperature rise of water by counter-propagating illuminations with two equivalent heat pulses of $50 \mathrm{~mJ}$. (A) Illumination of $1.89 \mu \mathrm{m}$ heat pulses with $3 \mathrm{~mm}$ diameter to $140 \mu \mathrm{m}$ thick water, and (B) illumination of $1.56 \mu \mathrm{m}$ heat pulses with $1.5 \mathrm{~mm}$ diameter to $2 \mathrm{~mm}$ thick water. Dot lines delineate the profiles of temperature rise by illuminations of each pulse from one side, and solid lines show the sum of those by counter-propagating illuminations of two heat pulses.

$5.7{ }^{\circ} \mathrm{C}$, respectively. Differences between the highest and lowest temperatures are $4.7{ }^{\circ} \mathrm{C}(22 \%)$ in panel $\mathbf{A}$ and 1.1 ${ }^{\circ} \mathrm{C}(20 \%)$ in panel B. Accordingly, the energy required to attain a T-jump as large as $5{ }^{\circ} \mathrm{C}$ in the heating conditions as shown in Fig. 1 is $30 \mathrm{~mJ}$ for a $1.89 \mu \mathrm{m}$ pulse and $100 \mathrm{~mJ}$ for a $1.56 \mu \mathrm{m}$ pulse, and for uniform heating of a sample (within $22 \%$ difference), the sample thickness should be several hundred micrometers for $1.89 \mu \mathrm{m}$ heating and several millimeters for $1.56 \mu \mathrm{m}$ heating.

Determination of Transient Temperature. Illumination of a heat pulse to a sample is followed by temperature changes of the laser-illuminated volume. The transient temperature of the heated volume can be determined by the intensity ratios of anti-Stokes to Stokes bands of a dissolved solute molecule. In this study an aqueous solution of $\mathrm{Na}_{2} \mathrm{MoO}_{4}(1.5 \mathrm{M})$ is used. Its Raman scattering is excited by another laser with variable delay times $(\Delta t)$ after illumination of heat pulses. In the case of nonresonant Raman scattering, the intensity (photon counting rate) of anti-Stokes $\left(I_{\mathrm{aS}}\right)$ and Stokes $\left(I_{\mathrm{S}}\right)$ bands of a selected molecular vibration with a wavenumber of $\tilde{v}_{\text {mol }}$ is related to the instantaneous temperature $(T)$ by Eq. 1,18

$$
\left(\frac{I_{\mathrm{aS}}}{I_{\mathrm{S}}}\right)_{T}=\left(\frac{\tilde{\nu}_{\mathrm{ex}}+\tilde{\nu}_{\mathrm{mol}}}{\tilde{\boldsymbol{v}}_{\mathrm{ex}}-\tilde{\boldsymbol{v}}_{\mathrm{mol}}}\right)^{3} \exp \left(-\frac{h c \tilde{\boldsymbol{v}}_{\mathrm{mol}}}{k_{\mathrm{B}} T}\right)
$$

where $\tilde{\nu}_{\text {ex }}$ and $k_{\mathrm{B}}$ are a Raman excitation wavenumber and Boltzmann constant, respectively. $\ddagger$ Boltzmann distribu-

\footnotetext{
\$ The third-power dependence of Raman scattering intensity on frequency in Eq. 1 appears when the intensity is defined in terms of photon numbers instead of energy flux, for which the fourth-power dependence is correct. Therefore, with detectors such as photodiode and charge-coupled device detectors, whose signal intensity is proportional to the number rate of incoming photons, Raman intensity should be represented with the third-power dependence as in Eq. 1.
} 
tion of energy among vibrational freedoms is postulated for Eq. 1, while it is usually established within a subnanosecond in the liquid phase. ${ }^{19}$ In the practical use of Eq. 1 , it is more convenient to determine the amount of temperature rise $(\Delta T)$ than the absolute temperature $(T)$. Suppose that the sample is initially placed in thermal equilibrium at $T_{0}$ and its temperature is raised by $\Delta T$ upon illumination of the heat pulse; the measurements of Raman intensities at the initial stage, $\left(I_{\mathrm{as}} / I_{\mathrm{S}}\right)_{T_{0}}$, and a transient state, $\left(I_{\mathrm{aS}} / I_{\mathrm{S}}\right)_{T_{0}+\Delta T}$, give $\Delta T$ according to Eq. 2:

$$
\ln \left(\frac{I_{\mathrm{aS}}}{I_{\mathrm{S}}}\right)_{T_{0}+\Delta T}-\ln \left(\frac{I_{\mathrm{aS}}}{I_{\mathrm{S}}}\right)_{T_{0}}=-\frac{h c \tilde{\nu}_{\mathrm{mol}}}{k_{\mathrm{B}}}\left(\frac{1}{T_{0}+\Delta T}-\frac{1}{T_{0}}\right)
$$

Accuracy of the temperature rise thus determined will be discussed later.

\section{EXPERIMENTAL}

NIR Pulse Generation with Hydrogen and Deuterium. The excitation pulse at $1.064 \mu \mathrm{m}$ for pumping $\mathrm{H}_{2}$ or $\mathrm{D}_{2}$ was obtained from a Q-switched Nd:YAG laser (GCR-150, Spectra Physics). The pulse energy was 560 $\mathrm{mJ}$ at $10 \mathrm{~Hz}$ and its width was $9 \mathrm{~ns}$ full width at halfmaximum (FWHM). To generate NIR pulses through stimulated Raman scattering, we examined three types of configurations as illustrated in Fig. 2: (A) a single-pass configuration, $(\mathbf{B})$ a half-resonator configuration, and $(\mathbf{C})$ a seeding-amplification configuration. For generation of $1.89 \mu \mathrm{m}$ NIR with $\mathrm{H}_{2}$, configuration $\mathrm{A}$ was sufficient. However, for generation of $1.56 \mu \mathrm{m} \mathrm{NIR}$ with $\mathrm{D}_{2}$, configurations $\mathbf{A}$ and $\mathbf{B}$ were insufficient and $\mathbf{C}$ was adopted. Hereafter a compressed-gas cell used for NIR pulse generation by SRS will be called a Raman shifter for the sake of convenience.

Figure 2A illustrates the single-pass configuration, in which the first Stokes line is generated by spontaneous Raman scattering and amplified within the pump pulse by self-seeding. The pump pulse was focused by a lens (L $1, f=600 \mathrm{~mm}$ ) into a Raman shifter (RS1) which is a $1.0 \mathrm{~m}$ long gas cell made of type-304 stainless steel with $12 \mathrm{~mm}$ inside effective diameter. Fused-silica windows with a diameter of $25.9 \mathrm{~mm}$ and thickness of 20.0 $\mathrm{mm}$ are used at the entrance and the exit of RS1 and were sealed by an O-ring with flanges. The out-going pulses were collimated with a lens (L2, $f=600 \mathrm{~mm})$ and separated by a Pellin-Broca prism (PBP) into pump, Stokes, and anti-Stokes pulses.

Figure 2B illustrates the half-resonator configuration, ${ }^{17,20}$ which uses an injection-seeding technique. A dichroic mirror (DM) and a mirror (M2) were added to the single-pass configuration; DM reflects $98.5 \%$ at $1.56 \mu \mathrm{m}$ and transmits $95 \%$ at $1.064 \mu \mathrm{m}$ for $45^{\circ}$ incidence, and M2 completely reflects the $1.56 \mu \mathrm{m}$ light. In the halfresonator configuration, the backward first SRS is reflected by M2 back to RS1 and is used as a seeding pulse, which is amplified within the same pump pulse. The temporal walk-off between the reflected seed and original pump pulses was $5 \mathrm{~ns}$.

Figure $2 \mathrm{C}$ illustrates the optical path of the seedingamplification configuration ${ }^{20,21}$ adopted in this experiment. The pump pulse was split into about $1: 5$ by a beamsplitter (BS) with variable reflection ratio. The weak portion was focused by a lens (L3, $f=1000 \mathrm{~mm}$ ) into RS1,
(A)

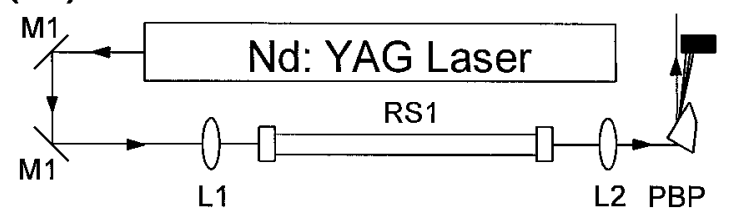

(B)

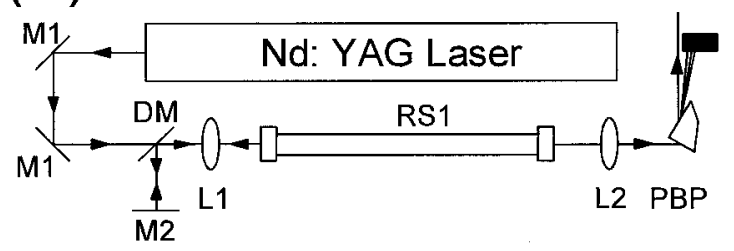

(C)

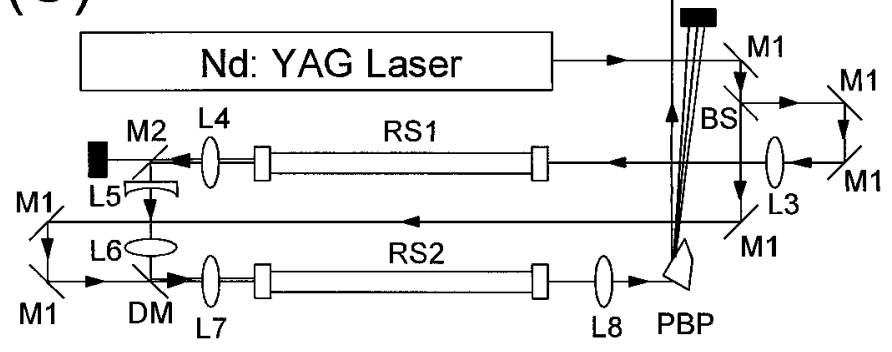

FIG. 2. Schematic diagrams of the $1.89 \mu \mathrm{m}$ and $1.56 \mu \mathrm{m}$ pulse generation by the stimulated Raman effect. (A) A single-pass configuration, (B) a half-resonator configuration, and (C) a seeding-amplification configuration. RS1, a compressed gas cell with length of $1.0 \mathrm{~m}$ and an effective diameter of $12 \mathrm{~mm}$; windows, noncoated quartz with a diameter of $25.9 \mathrm{~mm}$ and thickness of $20.0 \mathrm{~mm}$. RS2, a compressed gas cell with length of $1.1 \mathrm{~m}$ and an effective diameter of $20 \mathrm{~mm}$; windows, quartz AR-coated broadband filters from 1050 to $1600 \mathrm{~nm}$, with a diameter of $38.1 \mathrm{~mm}$ and thickness of $19.1 \mathrm{~mm}$. M1, mirror for $1064 \mathrm{~nm}$. M2, mirror for heat pulses. BS, beamsplitter for $1064 \mathrm{~nm}$ with variable reflection ratios. DM, dichroic mirror with high reflectance for heat pulses and high transmittance for $1064 \mathrm{~nm}$ pulses. L1, L2, L3, L4, L6, L7, and L8, plano-convex lenses. L5, plano-concave lens. PBP, PellinBroca prism.

where a seed pulse of the first Stokes line was generated through SRS. This seed pulse was collimated once with a convex lens ( $44, f=500 \mathrm{~mm}$ ) and then expanded to the same size as the other portion of the split pump pulse with a combination of a concave and convex lens (L5, $f$ $=-100 \mathrm{~mm}$; L6, $f=300 \mathrm{~mm}$ ). The seed pulse was overlain on the pump pulse spatially and temporarily by a dichroic mirror. The seed pulse and the pump pulse were focused by a lens (L7, $f=800 \mathrm{~mm}$ ) into an amplification Raman shifter (RS2), which is a $1.1 \mathrm{~m}$ long gas cell made of type-304 stainless steel with a $20 \mathrm{~mm}$ inside effective diameter. The fused-silica windows used at the entrance and the exit of RS2 were in practice the commercially available AR-coated broadband filters for 1050 to $1600 \mathrm{~nm}$ (transmission $>99 \%$ ) with a diameter of $38.1 \mathrm{~mm}$ and thickness of $19.1 \mathrm{~mm}$. Pressures of the compressed gas filled in RS1 and RS2 were set equal to make the wavelength of the seeding and amplified pulses coincide. ${ }^{22}$ This pressure adjustment improved the conversion efficiency from the pump pulse to the first Stokes line. The out-going pulses were collimated with a lens (L8, $f=600 \mathrm{~mm}$ ) and separated by PBP into pump, Stokes, and anti-Stokes pulses. 
Sample Cell and Illumination Geometry. For the Tjump experiment induced by $1.89 \mu \mathrm{m}$ heat pulses, a 100 $\mu \mathrm{m}$ thick sample cell with $1 \mathrm{~mm}$ thick quartz windows was used. The heat pulse dispersed with the Pellin-Broca prism $(62 \mathrm{~mJ})$ and one reflected at the surface of the prism $(8 \mathrm{~mJ})$ were used in configuration $\mathbf{A}$ in Fig. 2 with $\mathrm{H}_{2}$. These two pulses were incident into the sample cell from both sides with $45^{\circ}$-upward geometry. Energies of the divided heat pulses were not exactly equal in this experiment; therefore, the lower-energy pulse was more tightly focused (diameter: $1.1 \mathrm{~mm}$ ) at the sample point than the high-energy one (diameter: $2.3 \mathrm{~mm}$ ). A beam size was determined as a spot size with a burning paper. The actual pathlength through the sample along the propagation direction of heat pulses was $140 \mu \mathrm{m}$ in this configuration.

The Raman probe pulse was introduced to the sample cell so as to propagate colinearly with the high-energy heat pulse (diameter at the sample point: $1.3 \mathrm{~mm}$ ). The energy of the Raman probe pulse was $5 \mathrm{~mJ}$. Since the Raman scattering was collected mainly from the center of the heated volume, the slightly larger diameter of the probe pulse than that of the low-energy heat pulse would have no practical effect in this experiment. The sample was circulated with a peristaltic pump through the cell and the sample reservoir, which was kept at $25.0{ }^{\circ} \mathrm{C}$ by circulating temperature-controlled water. Between the peristaltic pump and the cell, two glass tubes were inserted as pressure reservoirs to remove pulsating flow. The average flow speed of the sample solution in the cell was $150 \mathrm{~cm} / \mathrm{s}$.

For the T-jump experiment induced by $1.56 \mu \mathrm{m}$ heat pulses, a $2 \mathrm{~mm}$ thick sample cell with $1 \mathrm{~mm}$ thick quartz windows was used. The heat pulse $(135 \mathrm{~mJ})$ at $1.56 \mu \mathrm{m}$ obtained from configuration $\mathbf{C}$ in Fig. 2 with $\mathrm{D}_{2}$ was split into two equal parts with a 50:50 beamsplitter. They were incident into the sample from both sides with an up-anddown counter-propagating geometry. The diameter of each pulse was $1.4 \mathrm{~mm}$ at the sample point. The Raman probe pulse, which was propagated colinearly with the up-going heat pulse, was focused below the sample cell before it illuminated the sample. This defocusing configuration prevented the Raman probe pulse from destroying cell windows through thermal lens effects induced by heat pulses. This problem was more crucial in the 1.56 $\mu \mathrm{m}$ heating due to thicker sample than that in the 1.89 $\mu \mathrm{m}$ heating. By the use of a cylindrical lens, the shape of the Raman probe pulse was modified to an elliptical shape at the sample point, where the major axis of the ellipsoid was directed to the collecting optics of the Raman scattering. The lengths of the major and minor axes were 1.2 and $0.5 \mathrm{~mm}$, respectively. The energy of the Raman probe pulse was lowered to $3 \mathrm{~mJ}$. The cell was held with brass blocks, and the temperature of the sample was kept at $25.0^{\circ} \mathrm{C}$ by circulating temperature-controlled water into the brass blocks. A thermal-conductive sheet was inserted between the cell and the brass blocks to improve thermal exchange. The sample was stirred by a small magnetic stirrer which was inserted into the brass blocks.

Measurements of Time-Resolved Raman Spectra. Raman scattering of molybdate ions was excited by the second harmonic $(532 \mathrm{~nm})$ of a Q-switched Nd:YAG la- ser (Spectra Physics, GCR-11) with the pulse width of 7 ns. The delay time $(\Delta t)$ of a Raman probe pulse from the illumination by a heat pulse was controlled by a pulse generator (Stanford Research Systems, DG535). The backward-scattered light in the $1.89 \mu \mathrm{m}$ heating experiment or the $90^{\circ}$-scattered light in the $1.56-\mu \mathrm{m}$ heating experiment was collected and focused onto an entrance slit of a $25 \mathrm{~cm}$ single-imaging spectrograph (Chromex, 250IS). The width of the entrance slit was $100 \mu \mathrm{m}$, while the widths of the image were 2.7 and $1.3 \mathrm{~mm}$ in the 1.89 and $1.56 \mu \mathrm{m}$ heating experiments, respectively. Therefore, the Raman scattering from the most heated volume (central part) was collected. A holographic notch filter (Kaiser Optical Systems, Super Notch-Plus) and an iris were inserted between the entrance slit of the spectrograph and the sample cell to reduce the stray light. A quartz polarization scrambler was placed in front of the entrance slit to remove the effect of polarization from the spectrograph throughput. In the case of the $90^{\circ}$ scattering geometry upon $1.56 \mu \mathrm{m}$ heating, another variable rectangular slit was placed at the side of the sample cell to reduce more effectively the stray light and Raman scattering of quartz windows. The dispersed light that passed through the spectrograph was detected with an intensified photodiode array (EG\&G PARC, Model 1421). The Stokes and anti-Stokes transient Raman spectra were obtained simultaneously.

One cycle of T-jump experiments involved a series of spectral measurements along increasing $\Delta t$ and decreasing $\Delta t$ and, in addition, the probe-only spectrum was measured at the end of individual series. In the $1.89 \mu \mathrm{m}$ heating experiments, one set of transient Raman spectra were the sum over five cycles. Total accumulation time at each delay time was $20 \mathrm{~min}$. In the $1.56 \mu \mathrm{m}$ heating experiments, three sets of transient Raman spectra, which were the sum over three cycles at each set, were obtained. Total accumulation time at each delay time was 6 min for each set.

\section{RESULTS}

Accuracy of Temperature Determination. Before applying Eq. 2 to determine the transient temperature rise following illumination of the heat pulse, we examined the accuracy of the method based on Eq. 2 for stationary states of the molybdate solution between 20.0 and 75.0 ${ }^{\circ} \mathrm{C}$. The stationary-state temperature was measured by a calibrated alumel-chromel thermocouple (accuracy: \pm 0.1 ${ }^{\circ} \mathrm{C}$ ) and was compared with the temperature determined by Eq. 2. Molybdate ions in an aqueous solution give sharp Raman bands at 317 and $897 \mathrm{~cm}^{-1}$ and a broad band at $837 \mathrm{~cm}^{-1}$, as reported. ${ }^{23}$ Figure 3 delineates the stationary-state Stokes (upper panel) and anti-Stokes Raman spectra (lower panel) of $\mathrm{Na}_{2} \mathrm{MoO}_{4}$ aqueous solution $(1.5 \mathrm{M})$ at 75.0 (A and $\left.\mathbf{A}^{\prime}\right)$ and $20.0{ }^{\circ} \mathbf{C}\left(\mathbf{B}\right.$ and $\left.\mathbf{B}^{\prime}\right)$. The spectral intensities are normalized in terms of the intensity of the Stokes $897 \mathrm{~cm}^{-1}$ band at $20.0{ }^{\circ} \mathrm{C}$ in the two panels. The ordinate scale of the anti-Stokes Raman spectra $\left(\mathbf{A}^{\prime}\right.$ and $\left.\mathbf{B}^{\prime}\right)$ is magnified by four times that of the Stokes spectra (A and $\mathbf{B})$.

All the Raman spectra from 20.0 to $75.0{ }^{\circ} \mathrm{C}$ were fitted to determine the area intensity: the 317 and $897 \mathrm{~cm}^{-1}$ bands by Lorentzian functions and the $837 \mathrm{~cm}^{-1}$ band by 

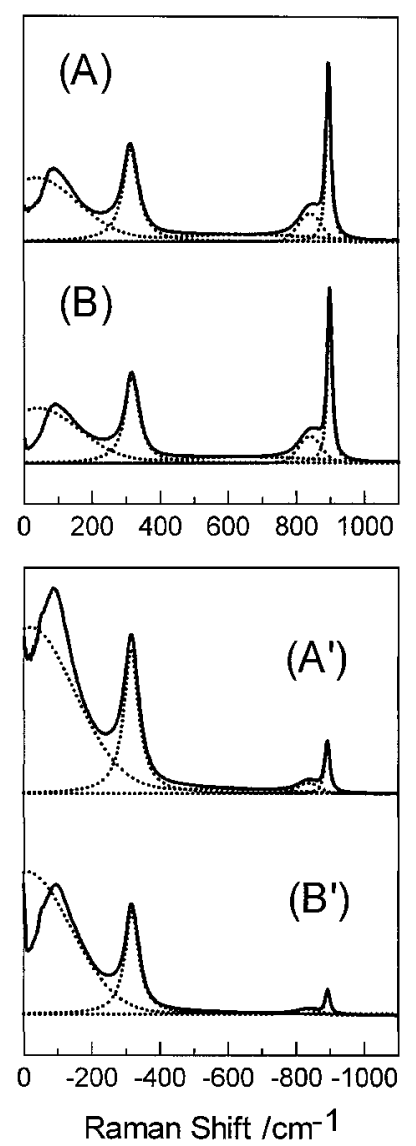

FIG. 3. Stationary-state Stokes (upper panel) and anti-Stokes Raman spectra (lower panel) of the $1.5 \mathrm{M} \mathrm{Na}_{2} \mathrm{MoO}_{4}$ aqueous solution excited at $532 \mathrm{~nm}$. (A) and $\left(\mathbf{A}^{\prime}\right)$ at $75.0 \pm 0.2{ }^{\circ} \mathrm{C},(\mathbf{B})$ and $\left(\mathbf{B}^{\prime}\right)$ at $20.0 \pm 0.1{ }^{\circ} \mathrm{C}$. The solid lines stand for the observed spectra in the right-angled scattering. The dotted lines illustrate the fitted bands and baselines-Lorentzian shapes for the 317 and $897 \mathrm{~cm}^{-1}$ bands and a Gaussian shape for the $837 \mathrm{~cm}^{-1}$ band. The intensities of these spectra are normalized to the Stokes $897 \mathrm{~cm}^{-1}$ band. The ordinate scales of $\mathbf{A}^{\prime}$ and $\mathbf{B}^{\prime}$ are expanded by a factor of 4 relative to those of $\mathbf{A}$ and $\mathbf{B}$. Stokes and antiStokes Raman spectra were obtained simultaneously.

a Gaussian function. Dotted lines in Fig. 3 delineate both baselines and fitted Raman bands at 317, 837, and 897 $\mathrm{cm}^{-1}$. With the use of $20.0{ }^{\circ} \mathrm{C}$ as the reference temperature $\left(T_{0}\right)$, the temperature differences from $T_{0}\left(\Delta T_{\mathrm{obs}}\right)$, were calculated according to Eq. 2 with ratios of $I_{\text {as }}$ to $I_{\mathrm{S}}$, which were obtained from the fitted parameters.

Comparison of the temperatures obtained according to Eq. 2, $T_{\text {obs }}\left(=\Delta T_{\text {obs }}+T_{0}\right)$, with the temperatures measured with a thermocouple, $T_{\text {tc }}$, is displayed in Fig. 4, which plots $T_{\text {obs }}$ as derived from the $317(\mathbf{A})$ and $897 \mathrm{~cm}^{-1}$ bands (B) against $T_{\text {tc }}$. The $837 \mathrm{~cm}^{-1}$ band was not used to determine $T_{\text {obs }}$, because its intensity obtained by fitted spectra contained larger uncertainty than that of the 317 and the $897 \mathrm{~cm}^{-1}$ bands due to the overlaps between intense 897 and broad $837 \mathrm{~cm}^{-1}$ bands. The differences between the Raman temperature and thermocouple temperature, $T_{\text {obs }}-T_{\text {tc }}$, are plotted against temperature in the upper panels of $\mathbf{A}$ and $\mathbf{B}$ in Fig. 4. It is recognized from these plots that the discrepancy between $T_{\mathrm{obs}}$ and $T_{\mathrm{tc}}$ is within $1.5{ }^{\circ} \mathrm{C}$ in the temperature range from 20.0 to $75.0{ }^{\circ} \mathrm{C}$ for both the 317 (A) and the $897 \mathrm{~cm}^{-1}$ (B) bands. This result confirms that temperatures of the sample can be determined with Eq. 2 with an accuracy of $\pm 1.5{ }^{\circ} \mathrm{C}$ in the
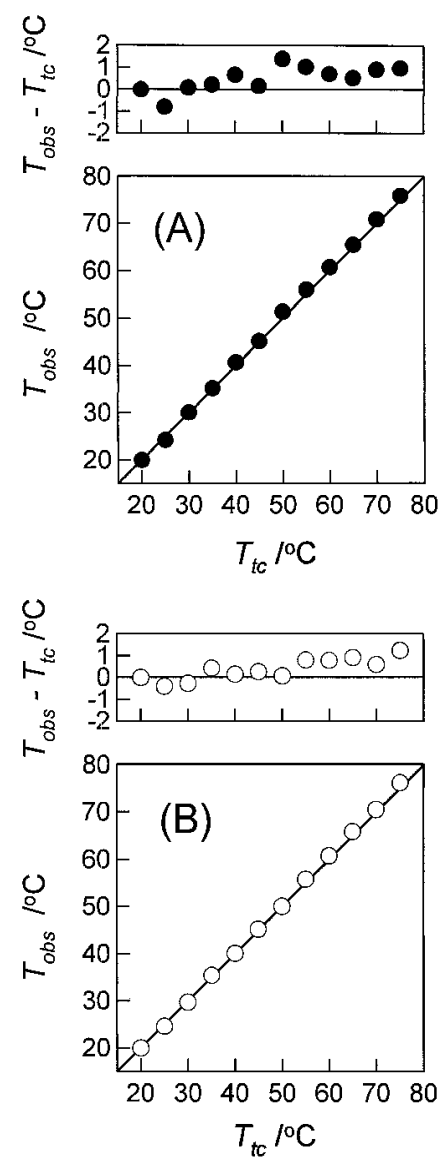

FIG. 4. Stationary-state temperature $\left(T_{\text {obs }}\right)$ of the $\mathrm{Na}_{2} \mathrm{MoO}_{4}$ solution determined from the anti-Stokes/Stokes Raman intensity ratios of molybdate ions in water is compared with the temperature $\left(T_{\mathrm{tc}}\right)$ measured with a calibrated alumel-chromel thermocouple: (A) $T_{\text {obs }}$ determined from $317 \mathrm{~cm}^{-1}$ bands and (B) $T_{\text {obs }}$ determined from $897 \mathrm{~cm}^{-1}$ bands. The solid lines stand for the straight lines $\left(T_{\mathrm{obs}}=T_{\mathrm{tc}}\right)$ for comparison. The upper panels in $\mathbf{A}$ and $\mathbf{B}$ show the plots of differences between the two obtained temperatures $\left(T_{\mathrm{obs}}-T_{\mathrm{tc}}\right)$.

temperature range from 20.0 to $75.0{ }^{\circ} \mathrm{C}$ when the 317 and $897 \mathrm{~cm}^{-1}$ bands are used in the present apparatus.

Characteristics of Generated $1.89 \mu \mathrm{m}$ Pulse. Hydrogen gas was compressed to $3.0 \mathrm{MPa}$ in RS1 for generation of a $1.89 \mu \mathrm{m}$ heat pulse. By using the single-pass configuration (A) in Fig. 2, we obtained $70 \mathrm{~mJ}$ pulses of $1.89 \mu \mathrm{m}$ at $10 \mathrm{~Hz}$ as the forward output. Intensity fluctuation among generated $1.89 \mu \mathrm{m}$ pulses was within $10 \%$. The spatial profile of the $1.89 \mu \mathrm{m}$ pulse was not a Gaussian shape but had a shape like a deformed doughnut. The surface temperature of RS1 around the focus point of pump pulses was raised upon prolonged pumping.

The highest output energy of the $1.89 \mu \mathrm{m}$ pulse was obtained at the hydrogen pressure of $3.0 \mathrm{MPa}$ in the range from 1.0 to 5.0 MPa. The output energy under $1.0 \mathrm{MPa}$ of hydrogen was very low $(16 \mathrm{~mJ})$ and increased as the $\mathrm{H}_{2}$ pressure increased. The output energy, however, was not always related to $\mathrm{H}_{2}$ pressure between 2.0 and 5.0 $\mathrm{MPa}: 46 \mathrm{~mJ}$ at $2.0 \mathrm{MPa}$ and $43 \mathrm{~mJ}$ at $5.0 \mathrm{MPa}$. The pulseto-pulse fluctuation and beam profile of $1.89 \mu \mathrm{m}$ pulses were barely dependent on $\mathrm{H}_{2}$ pressure in this pressure range.

Characteristics of Generated $1.56 \mu \mathrm{m}$ Pulse. Deuterium gas was compressed to $3.5 \mathrm{MPa}$ in RS1 for gen- 
eration of the $1.56 \mu \mathrm{m}$ pulse. With the use of configuration $\mathbf{A}$ in Fig. 2, the forward output energy of the 1.56 $\mu \mathrm{m}$ pulse was very low $(10 \mathrm{~mJ})$ at $10 \mathrm{~Hz}$ repetition; moreover, pulse-to-pulse fluctuations in energy and beam profile were significantly large. The conversion efficiency to $1.56 \mu \mathrm{m}$ by $\mathrm{D}_{2}$ was much less than that to $1.89 \mu \mathrm{m}$ by $\mathrm{H}_{2}$ in the same system (configuration A). The forward radiation from RS1 contained many rotational-vibrational components of stimulated Stokes and anti-Stokes Raman scattering. A large amount of backward radiation was also observed. The surface temperature of RS1 around the focus point of the pump pulse was raised upon prolonged pumping, as observed in the $1.89 \mu \mathrm{m}$ generation in configuration $\mathbf{A}$. The forward output energy of the 1.56 $\mu \mathrm{m}$ pulse, its intensity fluctuation, and the beam profile were barely dependent on $\mathrm{D}_{2}$ pressure in the range from 1.1 to $3.5 \mathrm{MPa}$. A rise in temperature of RS1 was observed for all values of pressure in this range.

To obtain more intense pulses at $1.56 \mu \mathrm{m}$, we examined configuration $\mathbf{B}^{17,20}$ in Fig. 2 with $3.5 \mathrm{MPa}$ of $\mathrm{D}_{2}$. The results were improved in comparison with the case of configuration $\mathbf{A}$, that is, $25 \mathrm{~mJ}$ pulses at $1.56 \mu \mathrm{m}$ were obtained at $10 \mathrm{~Hz}$ as forward output. However, after 20 min of pumping, the energy of the $1.56 \mu \mathrm{m}$ pulse was reduced to $10 \mathrm{~mJ}$ with a large intensity fluctuation. Consequently, although the NIR generation was significantly improved by configuration $\mathbf{B}$, the output energy was not sufficient for the purpose of T-jump and, moreover, the long-term stability was lacking.

Finally the seeding-amplification method illustrated by configuration $\mathbf{C}^{20,21}$ in Fig. 2 was examined with the pressure of RS1 and RS2 at 3.5 MPa. By adjusting the splitting ratio of the pump pulse with BS, we attained an output energy of $135 \mathrm{~mJ}$ for $1.56 \mu \mathrm{m}$ forward SRS pulses at $10 \mathrm{~Hz}$ repetition. This was more than 10 times larger than that obtained in configuration $\mathbf{A}$. The successive generation of $1.56 \mu \mathrm{m}$ pulses was stable for a period longer than half a day. The pulse-to-pulse fluctuation in intensity was suppressed within $10 \%$. The output pulses from RS 2 consisted of clearly separated light: (1) higher order anti-Stokes (second, third, and fourth) light with ring shapes, and (2) first Stokes light, pump light, and first anti-Stokes light with round shapes. The second Stokes scattering $(2.9 \mu \mathrm{m})$ was not observed in this experiment, presumably due to absorption by the glass of the optics. No backward scattering from RS2 was recognized.

Configuration $\mathbf{C}$ also provided an improved beam profile for the forward $1.56 \mu \mathrm{m}$ pulse. Though its spatial profile was not absolutely a Gaussian shape, the intensity maximum was located near the center, and intensity decreased going away from the center. The output beam profile in configuration $\mathbf{C}$ was much better than that of 1.89 or $1.56 \mu \mathrm{m}$ pulses in configuration $\mathbf{A}$. No temperature rise of the RS2 surface around the focus point of pump and seed pulses was recognized in configuration C, even after prolonged pumping of $\mathrm{D}_{2}$. This observation sharply contrasts with the observed temperature rise in configuration A with $\mathrm{H}_{2}$ or $\mathrm{D}_{2}$.

T-jump with $1.89 \mu \mathrm{m}$ NIR. Time-resolved Raman spectra of $\mathrm{MoO}_{4}{ }^{2-}$ solution $(1.5 \mathrm{M})$ after illumination of the $1.89 \mu \mathrm{m}$ heat pulses were obtained in the backward scattering geometry with delay times from $-1 \mu$ s to 10

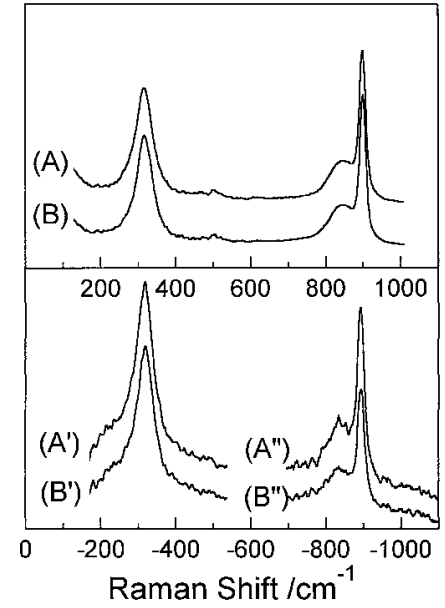

FIG. 5. Time-resolved Stokes (upper panel) and anti-Stokes Raman spectra (lower panel) of $\mathrm{MoO}_{4}{ }^{2-}$ solution $(1.5 \mathrm{M})$ with $100 \mu \mathrm{m}$ thickness observed just before and after the illumination with $1.89 \mu \mathrm{m}$ heat pulses: $\left(\boldsymbol{B}, \boldsymbol{B}^{\prime}\right.$, and $\left.\boldsymbol{B}^{\prime \prime}\right)$ at $-20 \mathrm{~ns}$ and $\left(\boldsymbol{A}, \boldsymbol{A}^{\prime}\right.$, and $\left.\boldsymbol{A}^{\prime \prime}\right)$ at $20 \mathrm{~ns}$. AntiStokes spectra $\left(\boldsymbol{A}^{\prime}\right.$ and $\boldsymbol{B}^{\prime}$ and $\boldsymbol{A}^{\prime \prime}$ and $\left.\boldsymbol{B}^{\prime \prime}\right)$ are vertically magnified by 4 and 20 times, respectively, of Stokes spectra $(\boldsymbol{A}$ and $\boldsymbol{B})$. The Raman spectra presented were obtained by subtracting the contribution of the quartz windows from the raw time-resolved Raman spectra.

ms. Figure 5 shows the Stokes (upper panel) and antiStokes (lower panel) time-resolved Raman spectra of $\mathrm{MoO}_{4}{ }^{2-}$ solution observed just before $(\Delta t=-20 \mathrm{~ns}, \boldsymbol{B}$, $\boldsymbol{B}^{\prime}$, and $\left.\boldsymbol{B}^{\prime \prime}\right)$ and after $\left(\Delta t=20 \mathrm{~ns}, \boldsymbol{A}, \boldsymbol{A}^{\prime}\right.$, and $\left.\boldsymbol{A}^{\prime \prime}\right)$ the illumination of heat pulses. $\S$ Anti-Stokes spectra $\left(\boldsymbol{A}^{\prime}\right.$ and $\boldsymbol{B}^{\prime}$ and $\boldsymbol{A}^{\prime \prime}$ and $\boldsymbol{B}^{\prime \prime}$ ) are magnified in the ordinate scale by 4 and 20 times, respectively, those of the Stokes spectra $(\boldsymbol{A}$ and $\boldsymbol{B})$. In Fig. 5, the spectrum of the quartz cell, which was measured after T-jump measurement without illumination of the heat pulses, was subtracted from the raw time-resolved Raman spectra observed, and then band fitting was performed. The band intensities of $\mathrm{MoO}_{4}{ }^{2-}$ were calculated in the same way with the stationary-state measurements. Transient temperature rises $\Delta T(t)$ at time $t$ from the reference temperature $T_{0}(25.0$ ${ }^{\circ} \mathrm{C}$ ) were obtained according to Eq. 2 . In the entire time region from $-1 \mu \mathrm{s}$ to $10 \mathrm{~ms}, \Delta T(t)$ values were determined with the $897 \mathrm{~cm}^{-1}$ band. Transient temperatures, $\Delta T(t)$, from $500 \mathrm{~ns}$ to $50 \mu \mathrm{s}$ were not determined correctly from the $317 \mathrm{~cm}^{-1}$ band, because the stray light from the probe pulse increased in this time region. The band at $837 \mathrm{~cm}^{-1}$ was not used in this procedure for the same reason that it was not used in the stationary-state measurements.

Figure 6 plots the transient temperature $\Delta T(t)$ in the nanosecond region (A) and in a longer time region $(\mathbf{B}$,

\footnotetext{
$\S$ Relative intensity of the $897 \mathrm{~cm}^{-1}$ band to the $317 \mathrm{~cm}^{-1}$ band in Fig. 5 is different from those in Figs. 3 and 7. This difference is caused by the difference in the angle between the polarization direction of the Raman probe light and the collecting direction of the scattered light; the angle with respect to the vertical axis was $90^{\circ}$ for Figs. 3 and 7 but $60^{\circ}$ for Fig. 5. The $897 \mathrm{~cm}^{-1}$ band is polarized but the 317 $\mathrm{cm}^{-1}$ band is depolarized. ${ }^{23}$ The polarized component in the geometry for Fig. 5 is relatively more unfavorable than the polarized component in the geometry for Figs. 3 and 7 because a component of polarized Raman scattering which is parallel to the collecting direction is not detected. However, this difference in polarization component is irrelevant to the temperature determination based on Eq. 2, because Eq. 2 is valid irrespective of polarization components.
} 

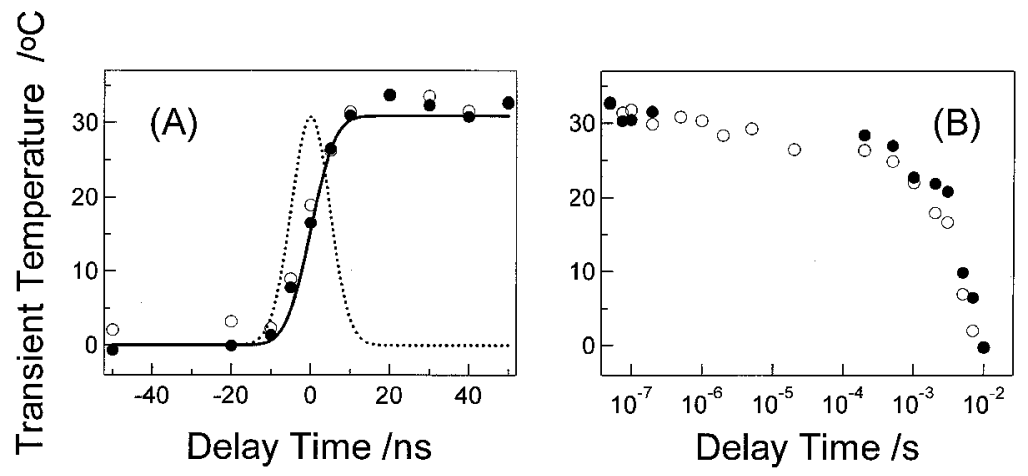

FIG. 6. Observed temperature rise in nanosecond region (A) and its longer time behavior (B) of the $\mathrm{Na}_{2} \mathrm{MoO}_{4}$ solution after illumination of 1.89 $\mu \mathrm{m}$ heat pulses. Filled and open circles denote the observed transient temperatures determined with the anti-Stokes/Stokes ratios of the 317 and $897 \mathrm{~cm}^{-1}$ bands of molybdate ions in water, respectively. The dotted line in A delineates the temporal cross-correlation of the heat pulse and Raman probe pulse. The solid line in $\mathbf{A}$ illustrates the expected temperature rise calculated from the cross-correlation.

logarithmic scale) following illumination of the $1.89 \mu \mathrm{m}$ heat pulses. The filled and open circles denote $\Delta T(t)$ determined from the 317 and $897 \mathrm{~cm}^{-1}$ bands, respectively. Good agreement between filled and open circles shows that Eq. 2 is applicable to transient temperature determination. It is recognized that a temperature rise of as much as $31{ }^{\circ} \mathrm{C}$ was attained by $1.89 \mu \mathrm{m}$ heating and that the elevated temperature remained until $1 \mathrm{~ms}$.

T-jump with $1.56 \mu \mathrm{m}$ NIR. Time-resolved Raman spectra of a $\mathrm{MoO}_{4}{ }^{2-}$ solution $(1.5 \mathrm{M})$ after illumination of $1.56 \mu \mathrm{m}$ heat pulses were obtained in the $90^{\circ}$ scattering geometry with delay times from $-200 \mathrm{~ns}$ to $80 \mathrm{~ms}$. Figure 7 shows the Stokes (upper panel) and anti-Stokes time-resolved Raman spectra (lower panel) just before $\left(-20 \mathrm{~ns}, \boldsymbol{B}, \boldsymbol{B}^{\prime}\right.$, and $\left.\boldsymbol{B}^{\prime \prime}\right)$ and after (20 ns, $\boldsymbol{A}, \boldsymbol{A}^{\prime}$, and $\left.\boldsymbol{A}^{\prime \prime}\right)$ the illumination of heat pulses. Anti-Stokes spectra $\left(\boldsymbol{A}^{\prime}\right.$ and $\left.\boldsymbol{B}^{\prime}\right)$ and $\left(\boldsymbol{A}^{\prime \prime}\right.$ and $\left.\boldsymbol{B}^{\prime \prime}\right)$ are magnified in the ordinate scale by 4 and 20 times, respectively, those of the Stokes spectra $(\boldsymbol{A}$ and $\boldsymbol{B})$. The time-resolved Raman spectra presented were used for calculation of the band intensities of $\mathrm{MoO}_{4}{ }^{2-}$ without any manipulation, because Raman

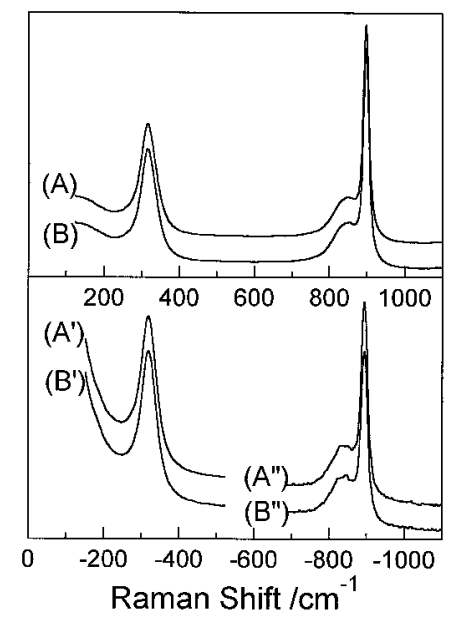

FIG. 7. Time-resolved Stokes (upper panel) and anti-Stokes Raman spectra (lower panel) of $\mathrm{MoO}_{4}{ }^{2-}$ solution $(1.5 \mathrm{M})$ with $2 \mathrm{~mm}$ thickness just before and after the illumination with $1.56 \mu \mathrm{m}$ heat pulses; $\left(\boldsymbol{B}, \boldsymbol{B}^{\prime}\right.$, and $\left.\boldsymbol{B}^{\prime \prime}\right)$ at $-20 \mathrm{~ns}$ and $\left(\boldsymbol{A}, \boldsymbol{A}^{\prime}\right.$, and $\left.\boldsymbol{A}^{\prime \prime}\right)$ at $20 \mathrm{~ns}$. Anti-Stokes spectra ( $\boldsymbol{A}^{\prime}$ and $\boldsymbol{B}^{\prime}$ and $\boldsymbol{A}^{\prime \prime}$ and $\boldsymbol{B}^{\prime \prime}$ ) are vertically magnified by 4 and 20 times, respectively, the Stokes spectra $(\boldsymbol{A}$ and $\boldsymbol{B})$. All the spectra are the raw time-resolved Raman spectra without any manipulation. scattering from quartz windows was well rejected spatially by the rectangular slit beside the sample cell as well as optically by the Notch filter. This slit also reduced the stray background so effectively that the intensities of the $317 \mathrm{~cm}^{-1}$ bands could be determined correctly in the time region from $500 \mathrm{~ns}$ to $50 \mu \mathrm{s}$ in spite of increased stray light. The procedures for determining a transient temperature rise $\Delta T(t)$ from the reference temperature $\left(25.0{ }^{\circ} \mathrm{C}\right)$ were the same as those in the previous $1.89 \mu \mathrm{m} T$-jump experiment. Raman bands at 317 and $897 \mathrm{~cm}^{-1}$ were used for these procedures, but the band at $837 \mathrm{~cm}^{-1}$ was not used for the same reason given for the stationary-state measurements. Three sets of $\Delta T(t)$ were obtained from three independent T-jump measurements.

Figures 8 and 9 plot the transient temperature rises $\Delta T(t)$ after illumination of $1.56 \mu \mathrm{m}$ heat pulses, which were obtained from the 317 and $897 \mathrm{~cm}^{-1}$ bands, respectively, in the nanosecond region (A) and in a longer time region (B, logarithmic scale). The marker points denote the average of three $\Delta T(t)$ values determined in three independent measurements, and error bars represent the magnitude of dispersion among them. The observed temperature rises from the 317 and $897 \mathrm{~cm}^{-1}$ bands are 8.2 and $9.2{ }^{\circ} \mathrm{C}$, respectively. Their difference is within the accuracy of temperature determination based on Eq. 2, as mentioned for the stationary-state measurements. When the laser-illuminated cylindrical volume, whose diameter and thickness are $1.4 \mathrm{~mm}$ (heat pulse) and $2 \mathrm{~mm}$ (sample thickness), respectively, is assumed to absorb $84 \%$ of the total energy of the $1.56 \mu \mathrm{m}$ heat pulse $(135 \mathrm{~mJ})$ on account of the absorption coefficient of $4 \mathrm{~cm}^{-1}$, the temperature rise expected for the solution with specific heat $1 \mathrm{cal} /{ }^{\circ} \mathrm{C}$ is $8.8{ }^{\circ} \mathrm{C}$, which is in good agreement with the experimental value $\left(8.2\right.$ and $\left.9.2^{\circ} \mathrm{C}\right)$.

Figures 8 and 9 also show that the elevated temperature lasts until $10 \mathrm{~ms}$. It is noted here that temperatures in the negative delay time region are higher than the reference temperature by $2.7{ }^{\circ} \mathrm{C}$ in Fig. 8 and by $2.4{ }^{\circ} \mathrm{C}$ in Fig. 9. However, the probe-only spectrum at the end of the series of measurements indicated the recovery of temperature to the reference temperature. Therefore, this raised temperature in the negative delay time region is attributed to insufficient heat conduction between the solution and the cell holder under successive heating at 10 

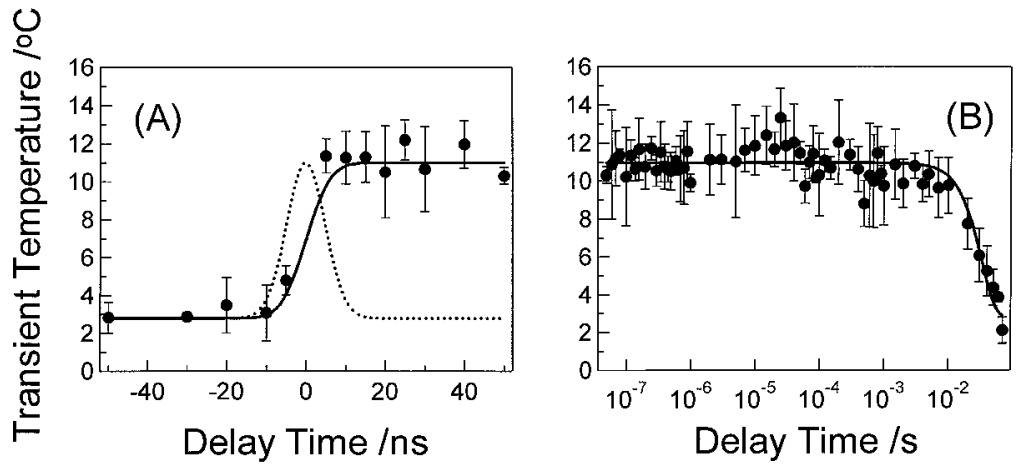

FIG. 8. Observed temperature rise in nanosecond region (A) and its longer time behavior (B) of the $\mathrm{Na}_{2} \mathrm{MoO}_{4}$ solution after illumination of 1.56 $\mu \mathrm{m}$ heat pulses. Filled circles denote the averaged values over three sets of observed transient temperature determined with the anti-Stokes/Stokes ratios of the $317 \mathrm{~cm}^{-1}$ bands of molybdate ions in water. Error bars show differences among them. The dotted line in A delineates the temporal cross-correlation between the heat pulse and Raman probe pulse. The solid line in A illustrates the expected temperature rise calculated from the cross-correlation. The solid line in $\mathbf{B}$ shows the expected temperature recovery based on replacement of heated volume with fresh sample.

Hz. Despite the insertion of a thermo-conductive sheet, the solution was slightly heated.

\section{DISCUSSION}

Effect of Seeding Amplification. In configuration A in Fig. 2, NIR pulses were generated by $\mathrm{H}_{2}$ with high energy and with high pulse-to-pulse stability, but this was not the case for $\mathrm{D}_{2}$. Configuration $\mathbf{C}$ was required to improve the conversion efficiency, pulse-to-pulse stability, and beam profile for $\mathrm{D}_{2}$. Thereby, the operations in configuration $\mathbf{C}$ are discussed from the next four viewpoints: (1) selective generation of light, (2) reduction of thermal gradient, (3) temporal and spatial overlap between seeding and pump pulses, and (4) contribution from generated anti-Stokes light.

(1) Selective Generation of Light. For generation of intense light by SRS, two types of selectivity are essential; one is nonlinear effect selectivity in forward SRS and the other is $J$-selectivity in the most intense $\mathrm{Q}(J)$ branch in the generation of the first Stokes light. To consider them in detail, the Raman gain coefficient is a useful parameter, ${ }^{24-26}$ and its $J$-dependence is derived in the Appendix for $\mathrm{Q}(J)$-branches of $\mathrm{H}_{2}$ and $\mathrm{D}_{2}$. From Eq. A.2, the coefficient $g_{\mathrm{R}}$ for the $\mathrm{Q}(J)$-branch of diatomic molecules such as $\mathrm{H}_{2}$ and $\mathrm{D}_{2}$ is proportional to the population at the rotational level $J$ in the electronic and vibrational ground state, $N_{\mathrm{J}}$, as

$$
g_{\mathrm{R}}[\mathrm{Q}(J)] \propto \frac{N_{J}\left(\tilde{v}_{\mathrm{p}}-\tilde{v}[\mathrm{Q}(J)]\right)}{\Delta \tilde{v}_{\mathrm{R}}[\mathrm{Q}(J)]}
$$

where $\tilde{v}_{p}$ is the wavenumber of pump light, $\tilde{v}[\mathrm{Q}(J)]$ is the wavenumber of the $\mathrm{Q}(J)$-branch, and $\Delta \tilde{\nu}_{\mathrm{R}}[\mathrm{Q}(J)]$ is the Raman bandwidth (FWHM). The refractive index is assumed to be unity in Eq. 3. The $J$-dependent Raman gain coefficients $g_{\mathrm{R}}[\mathrm{Q}(J)]$ calculated for $\mathrm{H}_{2}$ at $3.0 \mathrm{MPa}$ and $\mathrm{D}_{2}$ at $3.5 \mathrm{MPa}$ with Eq. $3 \|$ are shown in Table I, where the rotational populations at room temperature and the wavenumbers of $\mathrm{Q}(J)$-branches were calculated with Eq. A.3 and Eq. A.4, respectively, by using rotational-vibrational constants and nuclear degeneracy of $\mathrm{H}_{2}$ and $\mathrm{D}_{2}$ given in Table II. Raman bandwidths in Table I were calculated with Eq. A.5 by using collisional-narrowing $(A)$ and density-broadening $(B)$ factors given in Table III.

\footnotetext{
$\|$ For this calculation, $g_{\mathrm{R}}\left[\mathrm{H}_{2}, \mathrm{Q}(1)\right]=2.64 \mathrm{~cm} \mathrm{GW}^{-1}$ and $g_{\mathrm{R}}\left[\mathrm{D}_{2}, \mathrm{Q}(2)\right]$ $=0.45 \mathrm{~cm} \mathrm{GW}^{-1}$, as reported by Ottusch et al. ${ }^{22}$ for $532 \mathrm{~nm}$ pumping, were used. These values were obtained directly with the seeding-amplification technique. Raman gain coefficients of $\mathrm{H}_{2}$ and $\mathrm{D}_{2}$ were also given by Hanna et al. ${ }^{27}$ The reported values of $g_{\mathrm{R}}\left[\mathrm{H}_{2}, \mathrm{Q}(1)\right]$ are practically the same between these two papers. However, that of $g_{\mathrm{R}}\left[\mathrm{D}_{2}, \mathrm{Q}(2)\right]$ by Hanna et al. ${ }^{27}$ is about twice that by Ottusch et al. ${ }^{22}$
}
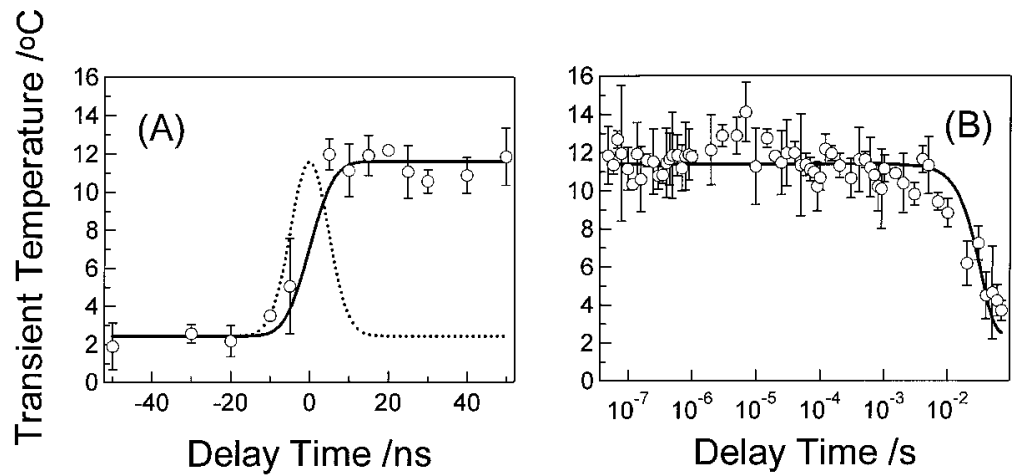

FIG. 9. Observed temperature rise in nanosecond region (A) and its longer time behavior (B) of the $\mathrm{Na}_{2} \mathrm{MoO}_{4}$ solution after illumination by the $1.56 \mu \mathrm{m}$ heat pulses. Open circles denote the averaged values over three sets of observed transient temperature determined with the anti-Stokes/ Stokes intensity ratios of the $897 \mathrm{~cm}^{-1}$ bands of molybdate ions in water. Error bars show differences among them. The dotted line in A delineates the temporal cross-correlation between the heat pulse and Raman probe pulse. The solid line in $\mathbf{A}$ illustrates the expected temperature rise calculated from this cross-correlation. The solid line in $\mathbf{B}$ shows the expected temperature recovery based on replacement of heated volume with fresh sample. 
TABLE I. Raman gain coefficients of $H_{2}$ at 3.0 MPa and of $D_{2}$ at 3.5 MPa under $1.064 \mu m$ excitation.

\begin{tabular}{|c|c|c|c|c|c|c|c|c|c|}
\hline & \multicolumn{4}{|c|}{$\mathrm{H}_{2}$} & \multicolumn{5}{|c|}{$\mathrm{D}_{2}$} \\
\hline & $\mathrm{Q}(0)$ & $\mathrm{Q}(1)$ & $\mathrm{Q}(2)$ & $\mathrm{Q}(3)$ & $\mathrm{Q}(0)$ & $\mathrm{Q}(1)$ & $\mathrm{Q}(2)$ & $\mathrm{Q}(3)$ & $\mathrm{Q}(4)$ \\
\hline$\tilde{v}\left(\mathrm{~cm}^{-1}\right)$ & 4161.1 & 4155.2 & 4143.4 & 4125.8 & 2993.6 & 2991.4 & 2987.2 & 2980.9 & 2972.6 \\
\hline$N_{J}(\%)$ & 13.0 & 65.8 & 11.7 & 9.0 & 18.3 & 20.5 & 38.4 & 11.4 & 9.3 \\
\hline$\Delta \tilde{\nu}_{\mathrm{R}}\left(\mathrm{cm}^{-1}\right)$ & 0.064 & 0.046 & 0.070 & 0.106 & 0.184 & 0.084 & 0.124 & 0.130 & 0.123 \\
\hline$g_{\mathrm{R}}\left(\mathrm{cm} \mathrm{GW}^{-1}\right)$ & 0.132 & $0.939^{\mathrm{a}}$ & 0.109 & 0.056 & 0.058 & 0.144 & $0.182^{\mathrm{a}}$ & 0.051 & 0.045 \\
\hline
\end{tabular}

${ }^{a}$ See Ref. 22.

It is recognized from Table $\mathrm{I}$ that the maximum value among $g_{\mathrm{R}}[\mathrm{Q}(J)]$ of $\mathrm{D}_{2}\left(0.18 \mathrm{~cm} \mathrm{GW}^{-1}\right.$ at $\left.J=2\right)$ upon $1.064 \mu \mathrm{m}$ pumping is about $20 \%$ that of $\mathrm{H}_{2}(0.94 \mathrm{~cm}$ $\mathrm{GW}^{-1}$ at $J=1$ ). Accordingly, the energy of pump light is less converted to the first Stokes light by $\mathrm{D}_{2}$ than by $\mathrm{H}_{2}$. As a result, backward-scattered light would be more stimulated by backward SRS and backward $\mathrm{SBS}^{25}$ in $\mathrm{D}_{2}$. In fact, a large amount of backward scattering was observed in configuration $\mathbf{A}$ with $\mathrm{D}_{2}$. This experimental result leads us to conclude that backward generation of additional light decreased the conversion of pump light into $1.56 \mu \mathrm{m}$ light in configuration $\mathbf{A}$ with $\mathrm{D}_{2}$. In contrast, no backward scattering was observed in configuration $\mathbf{C}$ with $\mathrm{D}_{2}$. This result indicates that the forward SRS overcomes the backward SRS and backward SBS in configuration $\mathbf{C}$ with $\mathrm{D}_{2}$. In other words, the selectivity in the forward SRS worked well in configuration $\mathbf{C}$ with $\mathrm{D}_{2}$. As a result, the conversion efficiency is much improved in configuration $\mathbf{C}$ over that in configuration $\mathbf{A}$ in Fig. 2.

On the other hand, with regard to the $J$-selectivity, Raman bands of $\mathrm{Q}(J)$-branches are well separated from each other even in high pressure at room temperature for both $\mathrm{H}_{2}$ and $\mathrm{D}_{2}$. The most intense branches at room temperature arose from $J=1$ for $\mathrm{H}_{2}$ and from $J=2$ for $\mathrm{D}_{2}$. However, intensity ratios among the $\mathrm{Q}(J)$-branches are very different between $\mathrm{H}_{2}$ and $\mathrm{D}_{2}$, because their rotational populations in the electronic and vibrational ground state are remarkably different (Table I), resulting mainly in different $J$-dependence for $g_{\mathrm{R}}[\mathrm{Q}(J)]$ between $\mathrm{H}_{2}$ and $\mathrm{D}_{2}$. For $\mathrm{H}_{2}$ it is recognized from Table I that the $g_{\mathrm{R}}[\mathrm{Q}(J)]$ values for $J \neq 1$ are much smaller than those for $J=1 ; 14 \%$ for $J=0$ and $12 \%$ for $J=2$ relative to that for $J=1$. Therefore, the energy depletion of the pump pulse due to $\mathrm{Q}(J)$-transitions different from $J=1$ can be neglected in Raman shifting with $\mathrm{H}_{2}$, and the first Stokes light due to the $\mathrm{Q}(1)$-transition is hence effectively generated. For $\mathrm{D}_{2}$, however, the $g_{\mathrm{R}}[\mathrm{Q}(J)]$ values for $J \neq 2$ are not so small relative to that for $J=2: 32 \%$ for $J=0,79 \%$ for $J=$ $1,28 \%$ for $J=3$, and $25 \%$ for $J=4$. Therefore, $\mathrm{Q}(J)$ branches from $J \neq 2$ would not be negligible for SRS in

TABLE II. Rotational and vibrational constants, and nuclear degeneracy of $\mathrm{H}_{2}$ and $D_{2}$.

\begin{tabular}{|c|c|c|c|}
\hline & & $\mathrm{H}_{2}$ & $\mathrm{D}_{2}$ \\
\hline \multicolumn{2}{|c|}{$B_{0}\left(\mathrm{~cm}^{-1}\right)^{\mathrm{a}}$} & 59.3392 & 29.9105 \\
\hline \multicolumn{2}{|c|}{$D_{0}\left(\mathrm{~cm}^{-1}\right)^{\mathrm{a}}$} & 0.04599 & 0.01134 \\
\hline \multicolumn{2}{|c|}{$\tilde{v}_{1-0}\left(\mathrm{~cm}^{-1}\right)^{\mathrm{a}}$} & 4161.137 & 2993.561 \\
\hline \multirow{2}{*}{\multicolumn{2}{|c|}{$\begin{array}{l}B_{1}-B_{0}\left(\mathrm{~cm}^{-1}\right)^{\mathrm{a}} \\
D_{1}-D_{0}\left(\mathrm{~cm}^{-1}\right)^{\mathrm{a}}\end{array}$}} & -2.9752 & -1.0623 \\
\hline & & -0.00276 & -0.00059 \\
\hline \multirow[t]{2}{*}{$g_{J}^{\mathrm{b}}$} & $J$ : even & 1 & 6 \\
\hline & $J:$ odd & 3 & 3 \\
\hline
\end{tabular}

${ }^{a}$ See Ref. 37.

${ }^{\mathrm{b}}$ See Ref. 36.
$\mathrm{D}_{2}$. In fact, the forward radiation pulses from RS 1 contained many components with different wavelengths in configuration $\mathbf{A}$ with $\mathrm{D}_{2}$. It is considered from this result that additional light pulses corresponding to many components of $\mathrm{Q}(J)$-branches were generated by SRS in configuration $\mathbf{A}$ with $\mathrm{D}_{2}$ and that their combinations were also generated by four-wave mixing (FWM). With the application of configuration $\mathbf{C}$, however, the forward radiation pulses from RS2 consisted of clearly separated Stokes and anti-Stokes light. This result indicates that SRS due to the $\mathrm{Q}(J)$-branch of $\mathrm{D}_{2}$ for $J=2$ suppressed those for $J \neq 2$. The $J$-selectivity in the most intense $\mathrm{Q}(J)$-branch of $\mathrm{D}_{2}$ worked well in configuration $\mathbf{C}$ for the generation of $1.56 \mu \mathrm{m}$ pulses, and hence it improved the conversion efficiency.

(2) Reduction of Thermal Gradient. In the interaction region of gaseous molecules with pump light, molecules are vibrationally excited by Raman pumping. Vibrational energy of excited molecules must be released as thermal energy. If they photodissociated by multiphoton absorption, recombination energy of dissociated atoms would also be released as thermal energy. Accordingly, a thermal gradient would be generated between the interaction region and its surroundings, if the interval between successive pump pulses is not long enough for the released heat to be dissipated from the interaction region. As a result, beam shapes of pump and generated pulses are distorted in passing through the interaction region, and the conversion efficiency to the first Stokes light is also reduced. In configuration $A$ with $\mathrm{H}_{2}$ and $\mathrm{D}_{2}$, in fact, the beam shapes of the first Stokes output were far from Gaussian shapes, and the surface temperature of RS1 around the focus point of pump pulses was raised upon prolonged pumping. It is deduced for configuration $\mathbf{A}$ in Fig. 2 that the released thermal energy remained in the interaction region upon $10 \mathrm{~Hz}$ pumping. Indeed, a large intensity fluctuation was observed among generated first Stokes pulses in configuration $\mathbf{A}$ with $\mathrm{D}_{2}$. However, it was not so large with $\mathrm{H}_{2}$. These results suggest that the thermal gradient of gases is a much more severe problem in $\mathrm{D}_{2}$ than in $\mathrm{H}_{2}$. In configuration $\mathbf{C}$ with $\mathrm{D}_{2}$, however, the beam shape of a $1.56 \mu \mathrm{m}$ pulse was refined, and a striking improvement in pulse-to-pulse stability was accomplished as well. Moreover, prolonged pumping did not raise the surface temperature of RS2 around the focus point of pump pulses. In conclusion, configuration $\mathbf{C}$ effectively reduced the thermal gradient in the interaction region of $D_{2}$ with the pump light and improved the beam quality in shape and in pulse-to-pulse stability.

(3) Temporal and Spatial Overlap between Seeding and Pump Pulses. The NIR generation with $\mathrm{D}_{2}$ was much improved by the use of configuration $\mathbf{C}$ in Fig. 2 regard- 
TABLE III. Collisional-narrowing $(A)$ and density-broadening $(B)$ factors.

\begin{tabular}{|c|c|c|c|c|c|c|c|c|c|}
\hline & \multicolumn{4}{|c|}{$\mathrm{H}_{2}{ }^{\mathrm{a}}$} & \multicolumn{5}{|c|}{$\mathrm{D}_{2}^{\mathrm{b}}$} \\
\hline & $\mathrm{Q}(0)$ & $\mathrm{Q}(1)$ & $\mathrm{Q}(2)$ & $\mathrm{Q}(3)$ & $\mathrm{Q}(0)$ & $\mathrm{Q}(1)$ & $\mathrm{Q}(2)$ & $\mathrm{Q}(3)$ & $\mathrm{Q}(4)$ \\
\hline$A\left(10^{-1} \mathrm{~cm}^{-1} \mathrm{~m}^{-3} \mathrm{~mol}\right)$ & 8.17 & 6.91 & 7.36 & 7.41 & 8.44 & 6.68 & 6.90 & 8.31 & 7.03 \\
\hline$B\left(10^{-5} \mathrm{~cm}^{-1} \mathrm{~m}^{3} \mathrm{~mol}^{-1}\right)$ & 2.35 & 1.68 & 2.58 & 3.90 & 13.0 & 5.90 & 8.76 & 9.21 & 8.67 \\
\hline
\end{tabular}

${ }^{a}$ See Ref. 38.

${ }^{\text {b }}$ See Ref. 39.

ing energy, beam shape, and pulse-to-pulse stability. Notable improvement was not obtained in configuration $\mathbf{B}$, although it also used the seeding technique. The reasons for the contrasting results in the two configurations are presumably associated with two kinds of overlap between the seed and pump pulses: temporal overlap and spatial overlap. Since the optical paths and beam sizes of the two pulses could be adjusted independently in configuration $\mathbf{C}$, the best overlaps were attained temporally and spatially. In configuration $\mathbf{B}$, on the other hand, the temporal walk-off between pulses was $5 \mathrm{~ns}$. Moreover, two pulses were not necessarily best overlapped spatially, because the size of the seed pulse could not be adjusted easily.

It is emphasized that the temporal overlap is an essential factor to generate the first Stokes light, since the pump energy is more depleted with the increase of its generation (saturation effect). If there is a slight temporal walk-off between the two pulses, the seed pulse would be amplified at an edge part of the pump pulse. In this experiment the best temporal overlap between the seed and pump pulses was estimated to be as much as $65 \%$ at their $5 \mathrm{~ns}$ difference. This observation indicates that temporal overlap significantly affects the conversion efficiency in NIR generation through the saturation effect. Moreover, the temporal difference of $5 \mathrm{~ns}$ resulted in reductions of output energy and of pulse-to-pulse stability upon prolonged pumping. Hence it is concluded that the best temporal overlap as well as best spatial overlap between the seed and pump pulses improved the conversion efficiency in configuration $\mathbf{C}$ with $\mathrm{D}_{2}$, and the improvement resulted in long-time stability of the generated NIR.

(4) Contribution of Generated Anti-Stokes Light. In configuration $\mathbf{C}$ with $\mathrm{D}_{2}$, the beam profiles observed for the pulses coming from RS2 were of round shape for the first anti-Stokes light and of ring shape for the higher order anti-Stokes light. The round shape of the first antiStokes light indicates that the first anti-Stokes light was mainly generated by SRS. Its generation, which actually reduces the conversion efficiency of the pump light to the first Stokes light, is believed to play an important role in depopulation of vibrationally excited molecules (mainly, $\mathrm{v}=1 \rightarrow \mathrm{v}=0$ ) and consequently to reduce the thermal gradient in the interaction region of $\mathrm{D}_{2}$ with pump light. The ring shapes of higher-order anti-Stokes light indicate that such pulses were generated mainly by FWM. Phase matching conditions for FWM would be satisfied with the focusing geometry of the seed and pump pulses by the lens (L5) in configuration $\mathbf{C}$ in Fig. 2. Therefore the higher-order anti-Stokes lights would be decreased by replacing L5 with a longer confocal lens.

Observed Temperature Rises in T-jump Experiments. The dotted line in Fig. 6A represents temporal cross-correlation between the $1.89 \mu \mathrm{m}$ heat pulse (9 ns) and Raman probe pulse $(7 \mathrm{~ns})$. The solid line shows the expected change of transient temperature calculated from this cross-correlation on the assumption that the energy dissipation of vibrationally excited water and thermal equilibration in the illuminated volume are much faster than the temporal width of the heat pulse. It is recognized that the observed $\Delta T(t)$ coincides very well with the expected curve of temperature rise. The same depictions are used in Figs. 8A and 9A for $1.56 \mu \mathrm{m}$ T-jump experiments. The observed $\Delta T(t)$ is also coincident with the expected curve of temperature rise in Figs. 8A and 9A. It is concluded from these results that the energy of the 1.89 or $1.56 \mu \mathrm{m}$ heat pulses was converted to thermal energy and equilibrated within its pulse width (9 ns). This observation demonstrates that the nanosecond T-jump can be attained by the nanosecond 1.89 or $1.56 \mu \mathrm{m}$ heat pulses.

Observed Temperature Recovery in T-Jump Experiments. Here the origins of observed temperature recovery in a long time region in Fig. 6B of $1.89 \mu \mathrm{m}$ heating and in Figs. 8B and 9B of $1.56 \mu \mathrm{m}$ heating are discussed. Possible origins of temperature recovery include (1) changes of thermal distribution in a sample and (2) replacement of heated volume by sample flowing. The extent of their contributions will be estimated separately below.

(1) Temporal Changes of Thermal Distribution. Thermal energy of the heated volume diffuses into other parts of the sample solution and is transferred to atmosphere through quartz windows. Therefore, even without flowing of sample, thermal distribution of heat energy changes through thermal diffusion and thermal transfer, the effects of which will be discussed separately. Temporal change of temperature is described by the thermal diffusion equation, ${ }^{28}$

$$
\frac{\partial T}{\partial t}=\kappa \nabla^{2} T
$$

where $T$ is the temperature, $\kappa$ is the thermal diffusivity, and $t$ is the time. The thermal diffusivity $\kappa$ is defined as

$$
\kappa=\frac{K}{\rho C}
$$

where $K$ is the thermal conductivity, $\rho$ is the density, and $C$ is the heat capacity.

Suppose that the two heat pulses, which are equivalent and have beam profiles of Gaussian shape, illuminate samples from both sides with counter-propagation geometry. This assumption is a crude approximation for the 1.89 $\mu \mathrm{m}$ T-jump experiment, but qualitative behavior of temporal temperature change can be investigated. Under this assumption, the two-dimensional intensity distribution, $I$, of each heat pulse is represented in the $(r, \theta)$ plane as 


$$
I(r, \theta)=\frac{E_{0}}{2} \frac{1}{2 \pi \sigma^{2}} \exp \left(-\frac{r^{2}}{2 \sigma^{2}}\right)
$$

where $E_{0} / 2$ is the energy of each heat pulse, and $\sigma$ is a measure of beam size.

Let us assume that $t=0$ is the time when the sample is illuminated by the two heat pulses from both sides and that the direction of the $z$-axis is along the sample thickness, which is equal to $2 l$; the temperature distribution at $t=0$ is given in cylindrical coordinates $(r, \theta, z)$ as

$$
T(r, \theta, z, t=0)-T_{0}=4 \pi \sigma^{2} l T_{\text {avg }} f(r, \theta, t=0) g(z, t=0) .
$$

The individual terms of the right side of Eq. (7) are given by

$$
\begin{aligned}
T_{\mathrm{avg}}= & \frac{1}{2 l} \int_{-l}^{l} \mathrm{~d} z T(r=0, z, t=0) \\
= & \frac{E_{0}(1-\exp (-2 a l))}{4 \pi \sigma^{2} l \rho c} \\
f(r, \theta, t=0)= & \frac{1}{2 \pi \sigma^{2}} \exp \left(-\frac{r^{2}}{2 \sigma^{2}}\right) \\
g(z, t=0)= & \frac{a}{2} \frac{\exp (a z)+\exp (-a z)}{\exp (a l)-\exp (-a l)} \\
= & \frac{a}{l} \frac{\exp (a l)+\exp (-a l)}{\exp (a l)-\exp (-a l)} \sum_{n=0}^{\infty} \frac{(-1)^{n} k_{2 n+1}}{a^{2}+k_{2 n+1}^{2}} \\
& \times \cos \left(k_{2 n+1} z\right)
\end{aligned}
$$

where $k_{2 n+1}=(2 n+1) \pi / 2 l . T_{0}$ denotes the temperature of sample before the illumination by heat pulses, and $T_{\text {avg }}$ is an averaged temperature along the $z$-direction at $r \stackrel{\text { ang }}{=}$ 0 immediately after the illumination. Functions $f(r, \theta, t$ $=0)$ and $g(z, t=0)$ represent the normalized distribution functions in the $(r, \theta)$ plane and along the $z$-axis, respectively. Parameter $a$ is given by $61 \times \sqrt{2} \ln 10 \mathrm{~cm}^{-1}$ for $1.89 \mu \mathrm{m}$ heating and $4 \times \ln 10 \mathrm{~cm}^{-1}$ for $1.56 \mu \mathrm{m}$ heating. The parameter $a$ for $1.89 \mu \mathrm{m}$ heating is magnified by the factor $\sqrt{2}$, because the $1.89 \mu \mathrm{m}$ pulses were illuminated at an angle of $45^{\circ}$ against the $z$-axis. Suppose that the temperature at the boundary is constant at $T_{0}$; the boundary conditions are represented as

$$
\begin{gathered}
T(r, \theta, z= \pm l, t)=T_{0} \quad \text { and } \\
T(r=\infty, \theta, z, t)=T_{0}
\end{gathered}
$$

Then the diffusion Eq. 5 can be solved under the initial conditions (Eqs. 7-10) and the boundary conditions (Eq. 11) $\operatorname{as}^{28}$

$$
T(r, \theta, z, t)-T_{0}=4 \pi \sigma^{2} l T_{\text {avg }} f(r, \theta, t) g(z, t)
$$

The time-dependent terms in the right side of Eq. 12 are represented as

$$
\begin{aligned}
f(r, \theta, t)= & \frac{1}{2 \pi\left(2 \kappa t+\sigma^{2}\right)} \exp \left(-\frac{r^{2}}{2\left(2 \kappa t+\sigma^{2}\right)}\right) \\
g(z, t)= & \frac{a}{l} \frac{\exp (a l)+\exp (-a l)}{\exp (a l)-\exp (-a l)} \\
& \times \sum_{n=0}^{\infty} \frac{(-1)^{n} k_{2 n+1}}{a^{2}+k_{2 n+1}^{2}} \cos \left(k_{2 n+1} z\right) \exp \left(-\kappa k_{2 n+1}^{2} t\right)
\end{aligned}
$$

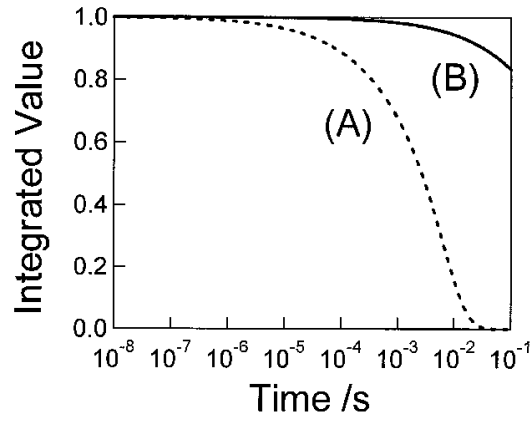

FIG. 10. The time dependence of the thermal transfer term. The integrated values of $g(z, t)$ from $z \equiv-l$ to $l$ are plotted against time: $(\boldsymbol{A})$ $2 l=100 \mu \mathrm{m}$ and $a=61 \times \sqrt{2} \times \ln 10 \mathrm{~cm}^{-1} ;(\boldsymbol{B}) 2 l=2 \mathrm{~mm}$ and $a$ $=4 \times \ln 10 \mathrm{~cm}^{-1}$.

The term $f(r, \theta, t)$ represents the temporal thermal distribution in the two-dimensional $(r, \theta)$-plane, i.e., thermal diffusion in the $(r, \theta)$-plane. On the other hand, the term $g(z, t)$ includes not only one-dimensional thermal diffusion in the $z$-axis but also the heat release through the two boundary surfaces at $z= \pm l$. But temporal diffusion in the $z$-axis is not measurable because our method determines the temperature of the sample which is averaged along the $z$-axis due to nonresonant Raman measurements. Accordingly, $g(z, t)$ represents mainly temporal behaviors due to the thermal exchange from the surfaces. For resonance Raman experiments where the intensity obtained close to the surface is most important, the $z$ dependence of $g(z, t)$ is the most important parameter.

Since the thermal diffusion term in the $(r, \theta)$ plane at $t=0$ represents the normal distribution, the value $2(2 \kappa t+$ $\left.\sigma^{2}\right)\left(=\left\langle r^{2}\right\rangle_{t}\right)$ determines the profile of $f(r, \theta, t)$. The value $2 \sqrt{2 \sigma^{2}}\left(=2 \sqrt{\left\langle r^{2}\right\rangle_{t=0}}\right)$ II is crudely approximated to the beam diameter measured with a burning paper: $1.7 \mathrm{~mm}$ for $1.89 \mu \mathrm{m}$ heat pulse, which is an average of two pulses, and $1.4 \mathrm{~mm}$ for the $1.56 \mu \mathrm{m}$ heat pulse. Insertion of $\kappa=0.14 \mathrm{~mm}^{2} \mathrm{~s}^{-1}$ at $25{ }^{\circ} \mathrm{C}$ into Eq. 13 causes $2 \sqrt{\left\langle r^{2}\right\rangle_{t}}$ at $100 \mathrm{~ms}$ to be $1.76 \mathrm{~mm}$ for the $1.89 \mu \mathrm{m}$ T-jump and 1.48 $\mathrm{mm}$ for the $1.56 \mu \mathrm{m}$ T-jump, respectively. These values suggest that the thermal diffusion within $100 \mathrm{~ms}$ is negligible in temperature recovery within the interval of successive T-jumps at $10 \mathrm{~Hz}$. This is owing to the sufficiently large beam size of the heat pulse for which temperature recovery in the center is negligible within $100 \mathrm{~ms}$.

The behavior of the thermal transfer term, $g(z, t)$, is dependent on sample thickness. The temporal behaviors of $g(z, t)$ are illustrated in Fig. 10, where the values integrated from $z=-l$ to $l$ are plotted against time: $(\boldsymbol{A}) 2 l$ $=100 \mu \mathrm{m}$ and $a=61 \times \sqrt{2} \ln 10 \mathrm{~cm}^{-1}$ for the $1.89 \mu \mathrm{m}$ T-jump, and (B) $2 l=2 \mathrm{~mm}$ and $a=4 \times \ln 10 \mathrm{~cm}^{-1}$ for the $1.56 \mu \mathrm{m}$ T-jump. Line $\boldsymbol{A}$ shows that the thermal transfer term $g(z, t)$ in the $1.89 \mu \mathrm{m}$ T-jump is remarkably timedependent within $100 \mathrm{~ms}$. However, it cannot be concluded only from this calculation that the origin of temperature recovery within a $100 \mu \mathrm{m}$ thickness is thermal transfer, because the surface conductance from water to quartz windows is postulated to be infinite in the boundary condition of Eq. $11 \mathrm{~A} .{ }^{28}$ Therefore, it is safe to say

If A cylinder having a diameter $2 \sqrt{2 \sigma^{2}}$ and height $1 / 2 \pi \sigma^{2}[=f(r=0$, $\theta, t=0]$ has the same volume as that of a Gaussian-shaped solid represented by $f(r, \theta t=0)=1 / 2 \pi \sigma^{2} \exp \left(-r^{2} / 2 \sigma^{2}\right)$. 

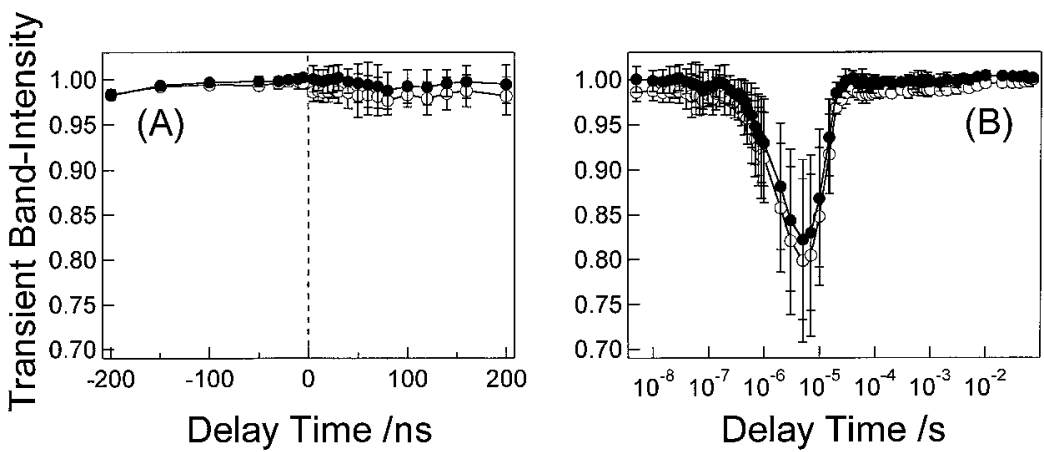

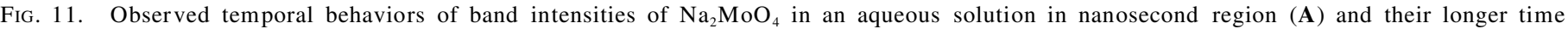

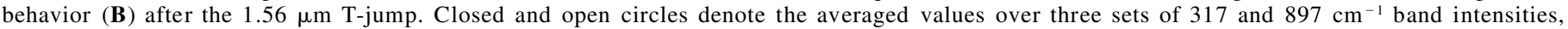
respectively. Error bars show differences among them.

that thermal transfer is a possible origin of temperature recovery in a sample as thin as $100 \mu \mathrm{m}$. On the other hand, it is recognized from line $\boldsymbol{B}$ that time dependence of $g(z, t)$ for the $2 \mathrm{~mm}$ thick sample within $100 \mathrm{~ms}$ is extremely small in the high conductance limit represented by Eq. $11 \mathrm{~A}$. Accordingly, thermal transfer within $100 \mathrm{~ms}$ is not a primary origin of temperature recovery in a sample as thick as $2 \mathrm{~mm}$.

(2) Contribution of Sample Replacement by Flowing. The above discussions suggest that the temperature distribution would be practically constant within $100 \mathrm{~ms}$ in $2.0 \mathrm{~mm}$ thick sample without flowing. Suppose that the sample flows with rate $v$ along the $x$-axis, which is perpendicular to the Raman collecting optics; the temperature distribution in the $(x, y)$ plane is given by

$$
T(x, y, t)-T_{0}=T_{\text {avg }} \exp \left(-\frac{(x-v t)^{2}+y^{2}}{2 \sigma^{2}}\right)
$$

Equation 15 is obtained from Eq. 12 by the ordinary transformation from cylindrical coordinates $(r, \theta, z)$ to rectangular coordinates $(x, y, z)$, followed by integration along the $z$-axis. The temperature difference, $\Delta T_{\text {obs }}(t)$, from $T_{0}$ of the volume, $V_{\text {col }}$, from which Raman scattering is collected, is proportional to

$$
\Delta T_{\mathrm{obs}}(t) \propto \exp \left(-\frac{v^{2}}{2 \sigma^{2}} t^{2}\right)
$$

This equation is valid when the optical window along the $x$ direction of $V_{\text {col }}$ is much smaller than the length along the $x$-axis of a heated volume. This condition was actually satisfied in the $1.56 \mu \mathrm{m}$ heating of this experiment, since the width of the entrance slit of the spectrograph was much smaller than that of the image of the Raman probe light on this slit.

Equation 16 predicts that the temperature recovery due to sample replacement of a heated volume is represented by a Gaussian function of time. The solid lines in Figs. $8 \mathrm{~B}$ and $9 \mathrm{~B}$ denote the temporal behavior of $\Delta T_{\mathrm{obs}}(t)$ according to Eq. 16, where an identical coefficient against time is used. Figures 8 and 9 show that the expected temperature recovery reproduces almost completely the experimental points. This means that the temperature recovery observed for longer delay times in the $1.56 \mu \mathrm{m}$ T-jump is caused by the replacement of the heated volume with fresh portion of sample due to flowing. It is hence concluded that the longer time limit of a T-jump measurement in a sample as thick as $2 \mathrm{~mm}$ is determined by replacement of sample by flowing at the present flowing rate, but not by thermal diffusion or by thermal transfer.

To examine the contribution of sample replacement to temperature recovery in the $100 \mu \mathrm{m}$ thick sample, we carried out an experiment in which the $1.89 \mu \mathrm{m}$ heat pulses illuminate the sample at $10 \mathrm{~Hz}$ repetition without sample flowing. It resulted in bubble generation in the sample and in breaking of cell windows. This means that the temperature of the sample heated by $1.89 \mu \mathrm{m}$ pulses was in effect when the next $1.89 \mu \mathrm{m}$ pulses arrived and that the temperature rise was partially additive. Thus the temperature recovery was not completed within $100 \mathrm{~ms}$ solely by thermal transfer. However, the temperature recovery was actually completed with sample flowing even for $100 \mu \mathrm{m}$ thick sample, as depicted in Fig. 6B. Therefore, it is concluded for a sample as thin as $100 \mu \mathrm{m}$ that the replacement of sample is one of the factors determining the longer time limit of T-jump experiments as well as thermal transfer.

Induced Thermal Effects upon T-jump. In the laserinduced T-jump experiments, the stray light of the probe pulse increased in the time region from $500 \mathrm{~ns}$ to $50 \mu \mathrm{s}$ following the illumination of 1.89 and $1.56 \mu \mathrm{m}$ heat pulses. The temporal behaviors of the time-resolved Raman intensities at 317 and $897 \mathrm{~cm}^{-1}$ bands in the 1.56 $\mu \mathrm{m}$ T-jump are depicted in Fig. 11, where their transient band intensities were obtained from the fitted parameters in the determination of the transient temperature. The two series of the experimental points in Fig. 11 show that the amount of observed Raman signals decreased between 1 and $10 \mu \mathrm{s}$. It has been known that very rapid heating of a solution generates a shock wave due to rapid thermal expansion, which results in the cavitation effect ${ }^{1,8}$ and, thus, loss of optical uniformity in the scattering volume of the sample solution. Therefore, it is interpreted that the shock wave and the cavitation effect cause crucial problems in the time-resolved Raman measurements, especially in terms of transient band intensities, although they are irrelevant to the transient temperature measurements according to Eq. 2. Figure 11, however, shows that the temporal changes in the band intensities at 317 and $897 \mathrm{~cm}^{-1}$ have a correlation. It means that time-resolved Raman spectra in the problematic region from $500 \mathrm{~ns}$ to 


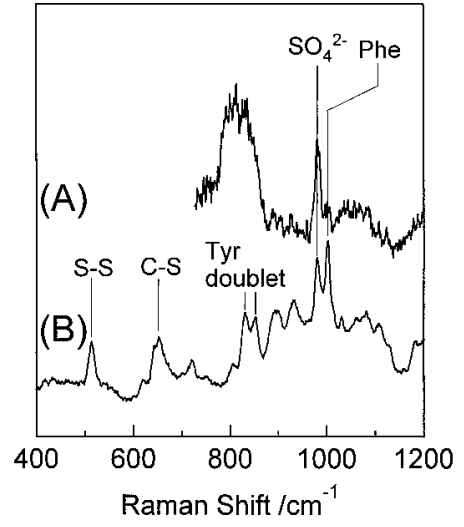

FIG. 12. Stationary Raman spectra of RNase A at $25.0^{\circ} \mathrm{C}$, excited by $532 \mathrm{~nm}$ light; $(\boldsymbol{A})$ observed for $150 \mathrm{mg} / \mathrm{mL}$ solution with the $100 \mu \mathrm{m}$ thick cell; $(\boldsymbol{B})$ observed for $100 \mathrm{mg} / \mathrm{mL}$ solution with the $2 \mathrm{~mm}$ thick cell. Ordinate scales of spectra $\boldsymbol{A}$ and $\boldsymbol{B}$ are arbitrary. The accumulation time for each spectrum was $30 \mathrm{~min}$. The low-frequency region in spectrum $\boldsymbol{A}$ is not displayed, because it could not be obtained due to the disturbance by Raman scattering of quartz windows.

$50 \mu$ s can be calibrated with the temporal behavior of the intensity.

Applicability of T-jump Apparatus to Time-Resolved Raman Studies of Proteins. Conformational changes of molecules in the initial steps of thermal excitation within milliseconds can be pursued by the combination of laser-induced T-jump and time-resolved Raman spectroscopy. In fact, the two types of the present T-jump apparatuses using 1.89 or $1.56 \mu \mathrm{m}$ heat pulses are applicable to time-resolved Raman measurements of $\mathrm{MoO}_{4}{ }^{2-}$ solution $(1.5 \mathrm{M})$ in time scales from nanoseconds to milliseconds. To examine their abilities with respect to time-resolved Raman measurements of proteins, we measured stationary-state Raman spectra of bovine pancreatic ribonuclease A (RNase A) with the same geometry as that for the time-resolved Raman measurements of the $\mathrm{MoO}_{4}{ }^{2-}$ solution without illumination of heat pulses.

The Raman spectra of RNase A obtained at $25.0{ }^{\circ} \mathrm{C}$ are delineated in Fig. 12: (A) observed for $150 \mathrm{mg} / \mathrm{mL}$ solution with $100 \mu \mathrm{m}$ thickness and $(\boldsymbol{B})$ observed for 100 $\mathrm{mg} / \mathrm{mL}$ solution with $2 \mathrm{~mm}$ thickness. The ordinate scales of spectra $\boldsymbol{A}$ and $\boldsymbol{B}$ are arbitrary. The accumulation time for the two spectra was same $(30 \mathrm{~min})$. It is recognized at a glance that spectrum $\boldsymbol{A}$ displays much worse features than spectrum $\boldsymbol{B}$. Spectrum $\boldsymbol{A}$ in the low-frequency region was distorted by broad Raman bands of quartz windows $\left(\sim 500 \mathrm{~cm}^{-1}\right)$ so strongly that the $\mathrm{S}-\mathrm{S}$ and $\mathrm{C}-\mathrm{S}$ stretching Raman bands could not be identified with the $100 \mu \mathrm{m}$ thick cell. The tyrosine (Tyr) doublet in spectrum $\boldsymbol{B}$ was well resolved, but that in spectrum $\boldsymbol{A}$ was hidden in the disturbance of stray light. A clearer band of phenylalanine residues (Phe) was given in spectrum $\boldsymbol{B}$ than in spectrum $\boldsymbol{A}$, although the band of sulfate ions around 980 $\mathrm{cm}^{-1}$ could not be compared due to their different concentrations between $\boldsymbol{A}$ and $\boldsymbol{B}$.** The $\mathrm{S}-\mathrm{S}$ and $\mathrm{C}-\mathrm{S}$ stretching bands as well as the tyrosine doublet are im-

\footnotetext{
** The lyophilized RNase A purchased from Sigma (type IIIA) contains sulfate ions. Because the sample solutions for Fig. 11A and 11B were prepared from different lots of the commercial RNase A, the concentrations of sulfate ions contained in each solutions were different. We did not standardize concentration in these experiments.
}

portant bands that are sensitive to the environmental conditions of side chains and thus are expected to reflect protein structures. Accordingly, measurements of timeresolved Raman spectra in the frequency region from 400 to $900 \mathrm{~cm}^{-1}$ are indispensable in order to discuss transient structures of RNase A involved in unfolding upon Tjump. The results shown in Fig. 12 mean that a thickness of $100 \mu \mathrm{m}$ is too thin for this purpose, but that the $2 \mathrm{~mm}$ thick sample can be used. Therefore the $1.56 \mu \mathrm{m}$ T-jump is applicable to time-resolved Raman experiments of protein unfolding, but the $1.89 \mu \mathrm{m}$ T-jump is not. For absorption, fluorescence, or ultraviolet resonance Raman measurements, the $100 \mu \mathrm{m}$ thick sample would be thick enough; therefore, the $1.89 \mu \mathrm{m}$ T-jump is a more suitable approach for those experiments because a larger T-jump is attained. The application of nanosecond T-jump to a time-resolved Raman study on the thermal unfolding of RNase A is reported separately. ${ }^{6}$

\section{SUMMARY}

We have constructed a system for the generation of 1.89 and $1.56 \mu \mathrm{m}$ intense heat pulses with $10 \mathrm{~Hz}$ repetition by stimulated Raman scattering of $\mathrm{H}_{2}$ and $\mathrm{D}_{2}$, respectively, and successfully applied the pulses to nanosecond T-jump experiments. The seeding-amplification technique, which was remarkably effective in raising the conversion efficiency, reducing the pulse-to-pulse fluctuations, and improving the beam quality, was indispensable for generation of $1.56 \mu \mathrm{m}$ heat pulses. To the authors' knowledge, this is the first report of successive generation of nanosecond giant pulses at $1.56 \mu \mathrm{m}$. It was confirmed with the anti-Stokes/Stokes intensity ratios in the time-resolved Raman spectra of $\mathrm{MoO}_{4}{ }^{2-}$ that a nanosecond temperature jump was indeed achieved by 1.89 or $1.56 \mu \mathrm{m}$ heat pulses. The long-time limit of the Tjump experiment for a sample as thick as $2 \mathrm{~mm}$ depended solely on the sample replacements due to flowing, but not on thermal diffusion and thermal transfer.

\section{APPENDIX}

$J$-Dependent Raman Gain Coefficients of $Q(J)$ Branches of $\mathbf{H}_{2}$ and $\mathbf{D}_{2}$. Raman differential cross sections of $\mathrm{H}_{2}$ and $\mathrm{D}_{2}$ are represented by the sum of the isotropic and anisotropic parts. ${ }^{29-32}$ The anisotropic parts, which are dependent on rotational levels, are negligible relative to the isotropic parts, ${ }^{33-35}$ which are independent of rotational levels for both $\mathrm{H}_{2}$ and $\mathrm{D}_{2}$. Thus, the $J$-dependent Raman gain coefficient of the $\mathrm{Q}(J)$-branches is derived from a basic representation ${ }^{24-26}$ as

$$
g_{\mathrm{R}}[\mathrm{Q}(J)] \propto \frac{N_{J} \tilde{\nu}_{\mathrm{S}}[\mathrm{Q}(J)]}{n_{\mathrm{s}}^{2} \Delta \tilde{\nu}_{\mathrm{R}}[\mathrm{Q}(J)]}
$$

where $N_{J}$ is the population at rotational level, $J$, in the electronic and vibrational ground state, $\tilde{v}_{\mathrm{S}}$ is the wavenumber of Stokes light, $\Delta \tilde{\nu}_{R}$ is the Raman bandwidth (FWHM), and $n_{s}$ is the refractive index. Replacement of $\tilde{v}_{\mathrm{S}}$ in Eq. A.1 with the wavenumber of pump light, $\tilde{v}_{\mathrm{p}}$, and the wavenumber of the $\mathrm{Q}(J)$-branch, $\tilde{v}[\mathrm{Q}(J)]$, yields Eq. A.2: 


$$
g_{\mathrm{R}}[\mathrm{Q}(J)] \propto \frac{N_{J}\left(\tilde{v}_{\mathrm{p}}-\tilde{v}[\mathrm{Q}(J)]\right)}{n_{\mathrm{s}}^{2} \Delta \tilde{v}_{\mathrm{R}}[\mathrm{Q}(J)]}
$$

The terms on the right side of Eq. A.2 are given by

$$
\begin{aligned}
N_{J}= & \frac{g_{J}(2 J+1) \exp \left(-\frac{h c}{k} \frac{F(J)}{T}\right)}{\sum_{J^{\prime}} g_{J^{\prime}}\left(2 J^{\prime}+1\right) \exp \left(-\frac{h c}{k} \frac{F\left(J^{\prime}\right)}{T}\right)} \\
\tilde{v}[\mathrm{Q}(J)]= & \tilde{\boldsymbol{v}}_{1-0}+\left(B_{1}-B_{0}\right) J(J+1) \\
& -\left(D_{1}-D_{0}\right) J^{2}(J+1)^{2} \\
\Delta \tilde{\nu}_{\mathrm{R}}[\mathrm{Q}(J)]= & \frac{A[\mathrm{Q}(J)]}{\rho}+B[\mathrm{Q}(J)] \rho
\end{aligned}
$$

where $g_{J}$ is the nuclear degeneracy ${ }^{36}$ and $F(J)$ is the energy of the rotational level, which is represented by ${ }^{37}$

$$
F(J)=B_{0} J(J+1)-D_{0} J^{2}(J+1)^{2}
$$

Equation A.5 for the Raman bandwidth, $\Delta \tilde{\boldsymbol{v}}_{\mathrm{R}}[\mathrm{Q}(J)]$, is represented by the sum of a diffusion term (the first term) and a density-broadening term (the second term). ${ }^{38,39}$

1. M. Eigen and L. DeMaeyer, in Techniques of Organic Chemistry, S. L. Friess, E. S. Lewis, and A. Weissberger, Eds. (Interscience, New York, 1963), Vol. 8, p. 895.

2. H. Hamaguchi and T. L. Gustafson, Ann. Rev. Phys. Chem. 45, 593 (1994).

3. Y. Mizutani and T. Kitagawa, Science 278, 443 (1997).

4. S. Ameen, Rev. Sci. Instrum. 46, 1209 (1975).

5. I. K. Lednev, A. S. Karnoup, M. C. Sparrow, and S. A. Asher, J. Am. Chem. Soc. 121, 4076 (1999).

6. K. Yamamoto, Y. Mizutani, and T. Kitagawa, Biophys. J. 79, 485 (2000).

7. J. V. Beitz, G. W. Flynn, D. H. Turner, and N. Sutin, J. Am. Chem. Soc. 92, 4130 (1970).

8. D. H. Turner, G. W. Flynn, N. Sutin, and J. V. Beitz, J. Am. Chem. Soc. 94, 1554 (1972).

9. A. P. Williams, C. E. Longfellow, S. M. Freier, R. Kierzek, and D. H. Turner, Biochemistry 28, 4283 (1989).

10. R. M. Ballew, J. Sabelko, C. Reiner, and M. Gruebele, Rev. Sci. Instrum. 67, 3694 (1996).

11. M. Gruebele, J. Sabelko, R. Ballew, and J. Ervin, Acc. Chem. Res. 31, 699 (1998).
12. P. A. Thompson, W. A. Eaton, and J. Hofrichter, Biochemistry 36, 9200 (1997).

13. Y. Mizutani, K. Yamamoto, and T. Kitagawa, in Old and New Views of Protein Folding, K. Kuwajima and M. Arai, Eds. (Elsevier, Amsterdam, 1999), pp. 85-94.

14. S. Williams, T. P. Causgrove, R. Gilmanshin, K. S. Fang, R. H. Callender, W. H. Woodruff, and R. B. Dyer, Biochem istry 35, 691 (1996).

15. C. M. Phillips, Y. Mizutani, and R. M. Hochstrasser, Proc. Natl. Acad. Sci. USA 92, 7292 (1995).

16. S. A. Asher, Z. Chi, J. S. W. Holtz, I. K. Lednev, A. S. Karnoup, and M. C. Sparrow, in International Conference on Raman Spectroscopy, A. M. Heyns, Ed. (John Wiley and Sons, Cape Town, 1998), p. 11.

17. Z. Chu, U. N. Singh, and T. D. Wilkerson, Opt. Commun. 75, 173 (1990).

18. S. D. Rassat and E. J. Davis, Appl. Spectrosc. 48, 1498 (1994).

19. T. Elsaesser and W. Kaiser, Ann. Rev. Phys. Chem. 42, 83 (1991).

20. S. E. Bisson, Appl. Opt. 34, 3406 (1995).

21. K. Komine and E. A. Stappaerts, Opt. Lett. 4, 398 (1979).

22. J. J. Ottusch and D. A. Rockwell, IEEE J. Quantum Electron. 24, 2076 (1988).

23. K. Nakamoto, Infrared and Raman Spectra of Inorganic and Coordination Compounds (John Wiley and Sons, New York, 1997), 5th ed.

24. N. Bloembergen, G. Bret, P. Lallemand, A. Pine, and P. Simova, IEEE J. Quantum. Electron. QE-3, 197 (1967).

25. W. Kaiser and M. Maier, in Laser Handbook, F. T. Arecchi and E. O. Schlz-DuBois, Eds. (North-Holland Publishing Company, Amsterdam, 1972), Vol. 2, p. 1077.

26. R. Loudon, The Quantum Theory of Light (Oxford University Press, Oxford, 1983), 2nd ed.

27. D. C. Hanna, D. J. Pointer, and D. J. Platt, IEEE J. Quantum Electoron. QE-22, 332 (1986).

28. H. S. Carslaw and J. C. Jaeger, Conduction of Heat in Solids (Oxford University Press, Oxford, 1959), 2nd ed.

29. T. C. James and W. Klemperer, J. Chem. Phys. 31, 130 (1959).

30. K. Altmann and G. Strey, J. Mol. Spectrosc. 44, 571 (1972).

31. H. W. Schroetter and H. W. Kloeckner, in Raman Spectroscopy of Gases and Liquids, A. Weber, Ed. (Springer-Verlag, Berlin, 1979), p. 123.

32. P. Baierl and W. Kiefer, J. Raman Spectrosc. 10, 197 (1981).

33. D. M. Golden and B. Crawford, Jr., J. Chem. Phys. 36, 1654 (1962).

34. W. Kolos and L. Wolniewics, J. Chem. Phys. 46, 1426 (1967).

35. R. W. Carlson and W. R. Fenner, Astrophys. J. 178, 551 (1972).

36. H. Eyring, J. Walter, and G. Kimball, Quantum Chemistry (John Wiley and Sons, New York, 1944).

37. B. P. Stoicheff, Can. J. Phys. 35, 730 (1957).

38. A. M. Toich, D. W. Melton, and W. B. Roh, Opt. Comm. 55, 406 (1985).

39. D. A. Russell and W. B. Roh, J. Mol. Spectrosc. 124, 240 (1987). 